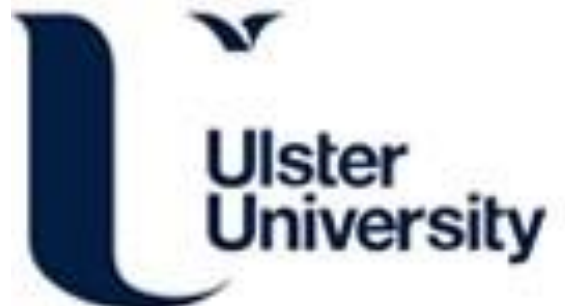

\section{Dynamics of blast wave and fireball after hydrogen tank rupture in a fire in the open atmosphere}

Molkov, V., Cirrone, D., Shentsov, V., Dery, W., Kim, W., \& Makarov, D. (2021). Dynamics of blast wave and fireball after hydrogen tank rupture in a fire in the open atmosphere. International Journal of Hydrogen Energy, 46(5), 4644-4665. https://doi.org/10.1016/j.ijhydene.2020.10.211

Link to publication record in Ulster University Research Portal

\section{Published in:}

International Journal of Hydrogen Energy

Publication Status:

Published (in print/issue): 19/01/2021

DOI:

10.1016/j.ijhydene.2020.10.211

\section{Document Version}

Author Accepted version

\section{General rights}

Copyright for the publications made accessible via Ulster University's Research Portal is retained by the author(s) and / or other copyright owners and it is a condition of accessing these publications that users recognise and abide by the legal requirements associated with these rights.

\section{Take down policy}

The Research Portal is Ulster University's institutional repository that provides access to Ulster's research outputs. Every effort has been made to ensure that content in the Research Portal does not infringe any person's rights, or applicable UK laws. If you discover content in the Research Portal that you believe breaches copyright or violates any law, please contact pure-support@ulster.ac.uk. 


\title{
DYNAMICS OF BLAST WAVE AND FIREBALL AFTER HYDROGEN TANK RUPTURE IN A FIRE IN THE OPEN ATMOSPHERE
}

Molkov V.V. ${ }^{1}$, Cirrone D.M.C. ${ }^{1}$, Shentsov V.V. ${ }^{1}$, Dery W. ${ }^{1}$, Kim W. ${ }^{2}$, Makarov D.V. ${ }^{1}$

${ }^{1}$ Ulster University, Hydrogen Safety Engineering and Research Centre (HySAFER), Newtownabbey, BT37 0QB, UK

${ }^{2}$ Hiroshima University, Department of Mechanical Systems Engineering, 1-4-1 Kagamiyama, HigashiHiroshima 739-8527, Japan

\begin{abstract}
This paper describes a CFD model of the blast wave and fireball dynamics after high-pressure hydrogen tank rupture in a fire in the open atmosphere. Experiments on rupture in a fire of tanks with nominal working pressure $35 \mathrm{MPa}$ and $70 \mathrm{MPa}$ are used to validate the model and get insights into underlying physical phenomena. Parametric studies are performed to understand the effect of different physical sub-models, numerical methods and other model parameters, e.g. instantaneous or inertial tank opening, on the convergence of simulations and closer reproduction of experiments. The model reproduces experiments well using different turbulence (RNG, Smagorinski-Lilly) and combustion (EDC, FRC) sub-models. It is demonstrated that hydrogen combustion at the contact surface between heated by starting shock air and cooled by expansion hydrogen at the initial stage of the process affects the blast wave strength, i.e. the peak pressure of the leading front and the blast wave impulse.
\end{abstract}

Keywords: hydrogen safety, tank rupture, blast wave, fireball, CFD model, validation

\section{Nomenclature}

\begin{tabular}{|l|l|}
\hline Acronyms & \\
\hline BCD & Bounded central differencing \\
\hline CD & Central differencing \\
\hline CFD & Computational fluid dynamics \\
\hline CFL & Courant-Friedrichs-Lewy \\
\hline CNG & Compressed natural gas \\
\hline CPU & Central processing unit \\
\hline CP & Combustion products \\
\hline CV & Control volume \\
\hline DO & Discrete ordinates \\
\hline EDC & Eddy dissipation concept \\
\hline EOS & Equation of state \\
\hline FRC & Finite rate chemistry \\
\hline ISAT & In-situ adaptive tabulation \\
\hline LES & Large-eddy simulation \\
\hline LFL & Lower flammability limit \\
\hline NWP & Nominal working pressure \\
\hline PISO & Pressure-implicit with the splitting of operators \\
\hline RNG & Renormalisation group \\
\hline SGS & Sub-grid scale \\
\hline TPRD & Thermally-activated pressure relief device \\
\hline UDF & User-defined function \\
\hline Greeks & \\
\hline$\pi$ & "pi" number, $3.141592 \ldots$ \\
\hline$\rho$ & Density, kg/m $\mathrm{m}^{3}$ \\
\hline$\gamma$ & Specific heat ratio \\
\hline Latins & Pre-exponential factor, $9.87 \cdot 10^{8}\left(\mathrm{~m}^{3} / \mathrm{mol} / \mathrm{s}\right)$, or burner area \\
\hline$A$ & Acceleration, $\mathrm{m} / \mathrm{s}^{2}$ \\
\hline$a$ & Co-volume constant, $1.584 \cdot 10^{-5} \mathrm{~m}^{3} / \mathrm{mol}$ \\
\hline$b$ & Speed of sound, $\mathrm{m} / \mathrm{s}$ \\
\hline$c$ & Specific heat at constant pressure, $\mathrm{J} / \mathrm{kg} / \mathrm{K}$ \\
\hline$c_{p}$ & \\
\hline
\end{tabular}




\begin{tabular}{|c|c|}
\hline$D$ & Distance from a tank, $\mathrm{m}$ \\
\hline$d$ & Tank diameter, $\mathrm{m}$ \\
\hline$\Delta E_{m}$ & Mechanical energy, $\mathrm{J}$ \\
\hline$\Delta E_{m}^{\text {ideal }}$ & Ideal gas mechanical energy, $\mathrm{J}$ \\
\hline$\Delta E_{m}^{r e a l}$ & Real gas mechanical energy, J \\
\hline$E_{a}$ & Activation energy, $3.1 \cdot 10^{7} \mathrm{~J} / \mathrm{kmol}$ \\
\hline$F$ & Force, $\mathrm{kg} \mathrm{m} / \mathrm{s}^{2}$ \\
\hline$H$ & Height, $\mathrm{m}$ \\
\hline HRR & Heat release rate, $\mathrm{W}$ \\
\hline$H R R / A$ & Specific heat release rate, $\mathrm{W} / \mathrm{m}^{2}$ \\
\hline$k$ & Thermal conductivity, $\mathrm{W} / \mathrm{m} / \mathrm{K}$ \\
\hline$L$ & Length, $\mathrm{m}$ \\
\hline$M$ & Mach number \\
\hline$m$ & Mass, kg \\
\hline$P, p$ & Pressure, $\mathrm{Pa}$ \\
\hline$P_{s t}$ & Non-dimensional pressure, $P_{s t}=p / p_{s}$ \\
\hline$P e$ & Peclet number \\
\hline$R$ & Universal gas constant, $8314.3 \mathrm{~J} / \mathrm{kmol} / \mathrm{K}$ \\
\hline$r$ & Reaction rate constant \\
\hline$S$ & Surface, $\mathrm{m}^{2}$ \\
\hline$T$ & Temperature, $\mathrm{K}$ \\
\hline$\Delta t$ & Timestep, $\mathrm{s}$ \\
\hline$t$ & Time, $\mathrm{s}$ \\
\hline$U, u$ & Flow velocity, $\mathrm{m} / \mathrm{s}$ \\
\hline$V$ & Volume, $\mathrm{m}^{3}$ \\
\hline$W$ & Width, $\mathrm{m}$ \\
\hline$\Delta x$ & CV size, $m$ \\
\hline$x$ & Axial tank direction \\
\hline$Z$ & Abel-Noble compressibility factor \\
\hline$z$ & Direction perpendicular to tank axis \\
\hline \multicolumn{2}{|c|}{ Subscripts } \\
\hline$g$ & Gas \\
\hline$m$ & Mechanical \\
\hline$s$ & Surrounding \\
\hline$s h$ & Shock \\
\hline \multicolumn{2}{|c|}{ Superscripts } \\
\hline burst & Burst \\
\hline ideal & Ideal gas \\
\hline Initial & Initial amount \\
\hline real & Real gas \\
\hline Total & Total amount \\
\hline tank & Tank \\
\hline
\end{tabular}

\section{INTRODUCTION}

The number of hydrogen-powered vehicles hitting the roads in different countries is increasing, with 15,000 new hydrogen filling stations slated for the year 2030 globally [1]. Case studies and statistics for hydrogen vehicles accidents are absent or very limited. However, the experience exists with CNG vehicles with 22.3 million worldwide since large-scale use began in the early 1980s [2]. The statistics for $\mathrm{CNG}$ vehicles shows that more than one-third of the total number of CNG tanks ruptured in a fire is due to pressure relief device failure [3]. Thus, it is practical to assume a non-zero failure probability of thermally activated pressure relief device (TPRD) for hydrogen vehicles. It is important to inform responders, including public, about the fire resistance rating of hydrogen storage tanks, i.e. time to rupture in a fire when TPRD either blocked or failed to be initiated, e.g. in a localised fire, and hazard distances due to the blast wave and fireball. Knowledge of fire resistance rating allows first responders to develop intervention tactics and strategies to save their life and provide public safety. 
To achieve the acceptable level of risk $10^{-5}$ for using hydrogen-powered cars on London roads, the onboard storage tanks fire resistance rating must be above $47 \mathrm{~min}$ [4]. This quantitative risk assessment study accounts for the TPRD failure probability in the localised fire of 0.5 [4]. The regulation requirement to assess risk implies the evaluation of high-pressure hydrogen tank rupture in fire consequences, i.e. hazards from the blast wave, fireball and projectiles. One of the debatable issues in the research community is whether there is a contribution of hydrogen combustion into the blast wave strength or not.

In 2015 the theoretical model of the blast wave and fireball after hydrogen tank rupture in a fire was developed and compared against experimental data [5]. Results of the theoretical analysis of experiments with $\mathrm{NWP}=35 \mathrm{MPa}$ tanks rupture in a fire [6-7] evidenced the importance of hydrogen reaction with air at the contact surface immediately after tank rupture on blast wave strength.

The experimental data on blast wave decay and fireball dynamics after hydrogen tank rupture in a fire are very limited. Here, the data obtained in fire tests performed in the USA with stand-alone tank $\mathrm{NWP}=35 \mathrm{MPa}$ [6-8] and two tests carried out in Japan with $\mathrm{NWP}=70 \mathrm{MPa}$ tanks [9] are used for validation of CFD model.

This study aims to develop and validate a CFD model to get insights into physics of formation and decay of blast wave and fireball after stand-alone hydrogen storage tank rupture in a fire in the open atmosphere, including the applicability of different sub-models of turbulence and combustion on simulation results.

\section{VALIDATION EXPERIMENTS}

USA test. The data on the fire test of stand-alone Type 4 hydrogen tank without TPRD performed in 2005 is published elsewhere [6-8]. The tank external length was $0.84 \mathrm{~m}$, diameter $0.41 \mathrm{~m}$, volume 72.4 L. Initial pressure was $34.3 \mathrm{MPa}$, temperature $300 \mathrm{~K}$ (1.64 kg of hydrogen). The tank ruptured $6 \mathrm{~min}$ $27 \mathrm{sec}$ after fire exposure $\left(H R R=370 \mathrm{~kW}, H R R / A=1.63 \mathrm{MW} / \mathrm{m}^{2}\right)$ when pressure and temperature raised to $35.7 \mathrm{MPa}$ and $312.15 \mathrm{~K}$ respectively (initial conditions for simulations). The tank was placed $0.2 \mathrm{~m}$ above the ground over a propane burner, see Fig. 1a. Three sensors were located perpendicular to the tank axis in a straight line at 1.9, 4.2 and $6.5 \mathrm{~m}$ from the tank centre. The fourth sensor was located along the tank axis at $4.2 \mathrm{~m}$. The measured maximum pressure was $300 \mathrm{kPa}$ and $41 \mathrm{kPa}$ at $1.9 \mathrm{~m}$ and $6.5 \mathrm{~m}$ respectively. The blast wave decayed faster along the tank axis $(28 \%$ reduction from $83 \mathrm{kPa}$ to $64.8 \mathrm{kPa}$ at $4.2 \mathrm{~m}$ ). The fireball diameter was $7.7 \mathrm{~m}$ at $45 \mathrm{~ms}$. The mechanical energy of compressed hydrogen is estimated as $7.33 \mathrm{MJ}$, a fraction of total chemical energy of hydrogen contributed to the blast wave maximum overpressure as 5.2\%, i.e. $10.3 \mathrm{MJ}$ [5]. This is higher than the mechanical energy. However, while the mechanical energy is released instantaneously the chemical energy is not.

Japanese tests. Two fire tests were conducted in Japan [9] on NWP=70 MPa tanks. The blast wave pressure was recorded at $5 \mathrm{~m}$ and $10 \mathrm{~m}$ perpendicular to the tank axis. In Test 1 (Fig. 1b), Type 4 tank of $35 \mathrm{~L}$ ruptured $21 \mathrm{~min}$ after fire exposure. The burst pressure was $94.54 \mathrm{MPa}$. The maximum blast wave overpressure at $5 \mathrm{~m}$ and $10 \mathrm{~m}$ was $110.5 \mathrm{kPa}$ and $23.4 \mathrm{kPa}$ respectively. In Test 2, Type 3 tank of $36 \mathrm{~L}$ ruptured $11 \mathrm{~min}$ after fire exposure (burst pressure $99.47 \mathrm{MPa}$ ). The maximum overpressure was $74.3 \mathrm{kPa}$ at $5 \mathrm{~m}$ and $23.4 \mathrm{kPa}$ at $10 \mathrm{~m}$. In Test 2, the maximum overpressure at the $5 \mathrm{~m}$ sensor was $30 \%$ less than in Test 1 , despite the slightly bigger volume of the tank and the burst pressure.

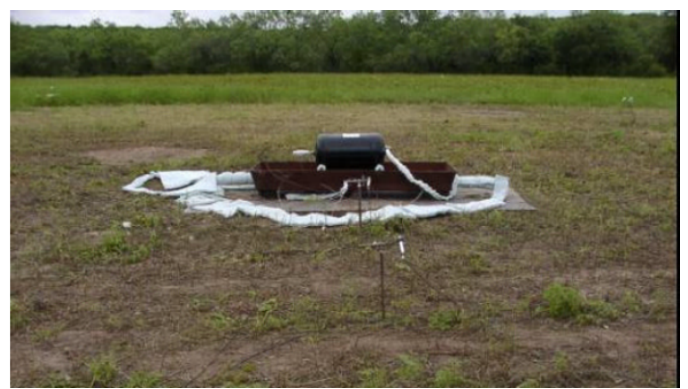

(a)

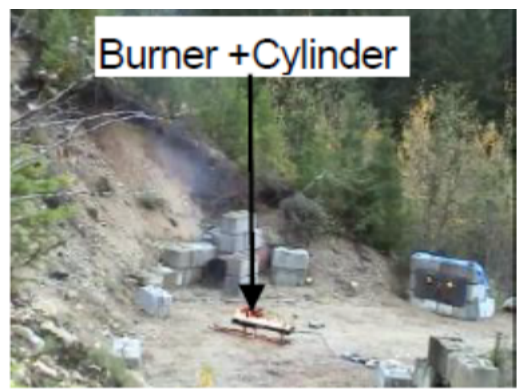

(b) 
Figure 1. Photo of hydrogen cylinder located above the burner pan in the experimental setup: (a) - the USA test [6], (b) - Japanese Test 1 [9].

\section{NUMERICAL MODELLING}

\subsection{Starting shock and ideal gas chemistry}

Hydrogen at storage pressures 35-100 MPa behaves as real gas. The pressure of outward propagating blast wave after tank rupture is the starting shock pressure, which is significantly below the storage pressure [5]. The calculated dimensionless starting shock pressure, $P_{s t}$, is 53.17 for USA test (real gas inside the cylinder, ideal gas outside). This corresponds to the absolute pressure 5.4 MPa once multiplied by the atmospheric pressure $0.101325 \mathrm{MPa}$. When considering the speed of sound of an ideal gas for the pressurised gas in the vessel, as in the numerical simulations, the somewhat lower starting shock pressure is calculated (4.4 MPa). For Japanese tests, the starting shock pressure is $7.50 \mathrm{MPa}$ and $7.86 \mathrm{MPa}$ for Test 1 and Test 2 respectively. Thus, in all cases, the pressure in the starting shock is less than $10 \mathrm{MPa}$, i.e. hydrogen combustion at the contact surface with air can be considered as a reaction of ideal gases for which chemistry is well defined in the literature. Simulations with different real gas EOS demonstrated that a numerical solution produces untenable results averting convergence, and increases the calculation time drastically [10]. All simulations here are performed with the ideal gas EOS.

\subsection{Mechanical energy conservation by tank volume scaling}

The mechanical energy of compressed ideal gas:

$\Delta E_{m}^{\text {ideal }}=\frac{\left(p_{g}-p_{s}\right) V}{\gamma-1}$.

The mechanical energy of compressed real gas is somewhat smaller for the same volume and pressure:

$\Delta E_{m}^{\text {real }}=\frac{\left(p_{g}-p_{s}\right)(V-m b)}{\gamma-1}$.

To conserve the mechanical energy of compressed hydrogen at real gas conditions, the tank volume with "ideal gas" in the simulations is scaled down as:

$V_{\text {ideal }}=V_{\text {real }}-m b$.

For the USA test, the cylinder volume is reduced by $17.5 \%$ from $72.2 \mathrm{~L}$ to $59.5 \mathrm{~L}$. In Japanese tests, the tank volume is scaled-down from $35 \mathrm{~L}$ to $23.9 \mathrm{~L}$ (Test 1), and from $36 \mathrm{~L}$ to $24.6 \mathrm{~L}$ (Test 2).

\subsection{Description of the CFD model, calculation domain, mesh, boundary and initial conditions}

Simulations are performed using Fluent as the computational engine. The pressure-based solver with PISO pressure-velocity coupling algorithm is used. The LES approach is implemented for turbulence and turbulent combustion modelling as the DNS is impossible on large scales characteristic for safety problems and the RANS averaging through different scales does not make simulations more representing physics compared to LES. The use of LES is supported by the disparity between time scales for blast wave propagation and turbulence; the fact that hydrogen expansion was driven by pressure gradients rather than shear flows; additionally, the comparatively large scales, low velocity and low flame stretch rates characterising fireball formation make their LES preferable. The governing equations are based on the filtered conservation equations for mass, momentum, and energy in their compressible form. The ground is specified as the adiabatic no-slip impermeable wall (simulations with non-adiabatic boundary did not show any effect on the pressure dynamics). The external non-reflecting boundary in the air is defined as pressure outlet with gauge pressure equal to zero.

The second-order interpolation scheme is used for pressure to improve simulation accuracy. The second-order upwind scheme is used for convective terms, given that the flow is characterised by Peclet number higher than 2, $P e=\left(\rho c_{p} u \Delta x\right) / k$. The first-order accurate time-step discretisation is employed for time advancement. Change to the second-order scheme for time advancement for the case with constant time step did not cause any difference in the pressure dynamics. 
The original time step adapting technique is developed by Dr Shentsov and employed here to maintain a constant CFL number and thus increase time step as the shock and flow velocities reduce in the course of an explosion. The CFL number is defined as CFL $=(u+c) \Delta t / \Delta x$. The UDF algorithm looks at each time step for a CV with a maximum value of CFL number and then calculates the speed of sound and extracts flow velocity in this cell. Then the UDF calculates the time step, using the specified CFL value that should not be exceeded, as $\Delta t=C F L \times \Delta x /(|u|+c)$. The CFL definition uses the speed of sound. However, in our problem, we have another characteristic velocity, i.e. shock propagation velocity, which is higher than the speed of sound. Thus, a solution convergence is expected at CFL $<1$. This technique provides an automated increase of the time step during simulations, with a significant saving of computational time compared to the constant time step simulations. The convergence was reached when residuals were smaller than $10^{-6}$ for all variables including energy, the calculations are carried out with 20 iterations per time step.

The CFD model is compared against experiments with the use of two widely applied SGS turbulence sub-models, i.e. the Smagorinsky-Lilly [15] and the RNG [14], and two sub-models of combustion, i.e. the EDC [11] and the FRC model by Fluent. The EDC sub-model is known for the ability to model the effect of turbulence-chemistry interaction on the combustion rate through so-called fine scales [11]. The FRC sub-model assumes that chemical reaction takes place in the whole control volume rather than in fine scales only. Both the EDC and FRC sub-models could include either one-step Arrhenius chemistry or 37 reactions chemical mechanism published elsewhere [13]. To reduce the calculation time by a factor of four one-step Arrhenius chemistry is applied in most of the simulations unless it is stated that 37 reactions chemical mechanism is applied. The USA test is simulated using the Smagorinsky-Lilly and EDC sub-models demonstrated good performance to reproduce experiments in our previous studies of other hydrogen safety related phenomena. The range of sub-models for simulation of Japanese tests is extended to the use of RNG and the Smagorinsky-Lilly for SGS turbulence and the FRC along with the EDC for combustion to test the CFD model flexibility to different sub-models.

The outlining hemispherical domain of $100 \mathrm{~m}$ (USA test) or $88 \mathrm{~m}$ (Japanese tests) in diameter (to minimise any boundary effects) is divided into three zones, catering to the various dynamics of the blast wave and fireball (see Fig. 2a). The tank is placed centred in the domain, $20 \mathrm{~cm}$ above the ground for the USA test and $1 \mathrm{~m}$ for the Japanese tests. A hexahedral mesh is applied. The mesh ranged from 1-3 cm composing the hydrogen tank. This includes the near tank surface to better resolve the high gradients of velocity and pressure (see Figs. $2 \mathrm{~b}$ and $2 \mathrm{c}$ ). A maximum expansion ratio of 1.1 was used in proximity of the tank, while 1.2 was applied for distances greater than $10 \mathrm{~m}$. A thorough analysis of the mesh is outlined in Section 4.2.9.

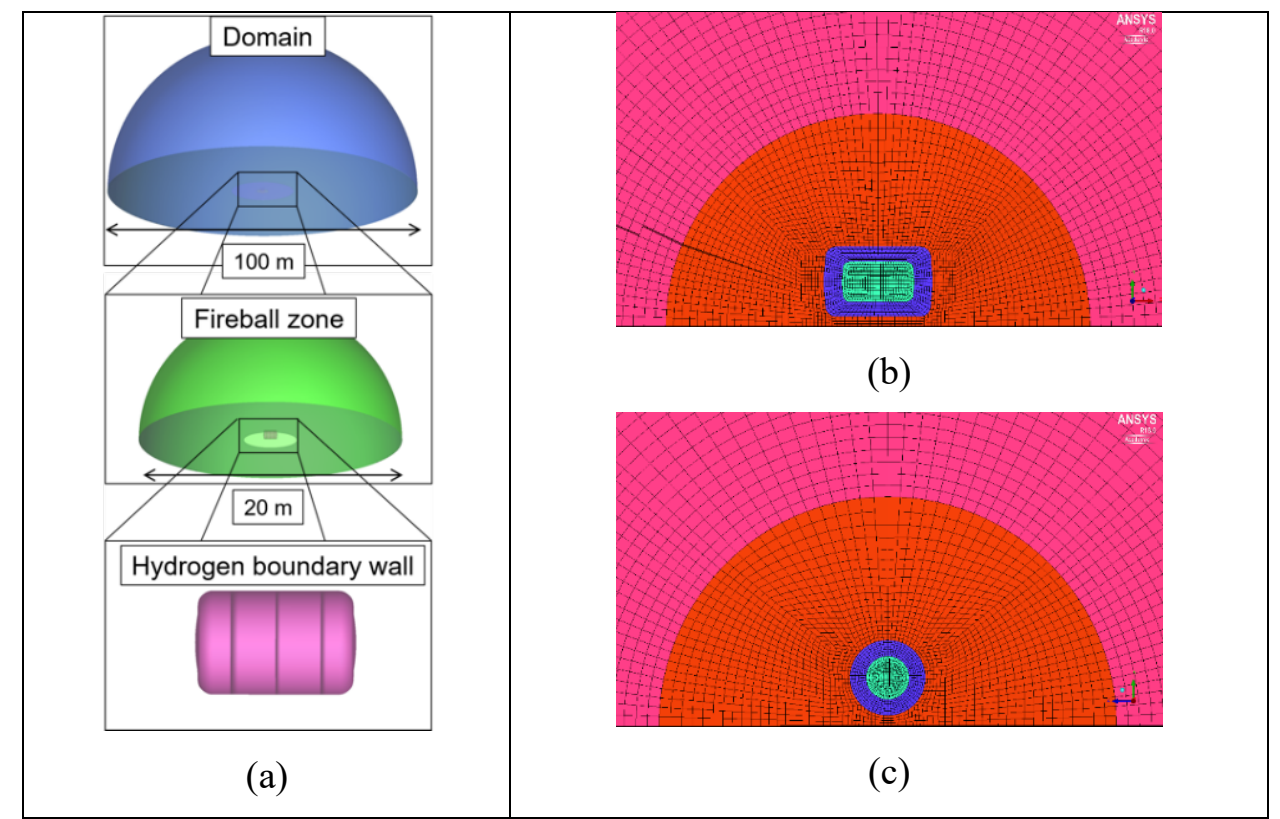


Figure 2. (a) - the computational domain including the fireball zone and the hydrogen tank zone, (b) and (c) - the hexahedrally meshed area in the near vicinity of the tank $(2.5 \mathrm{~m})$ in axial and perpendicular to the tank directions respectively.

The hexahedral mesh of 311,114 CVs in $100 \mathrm{~m}$ hemispherical calculation domain is applied for the USA test, with initial conditions: the tank burst pressure $35.7 \mathrm{MPa}$ and temperature $312.15 \mathrm{~K}$, hydrogen mass fraction 1, ambient pressure $0.101325 \mathrm{MPa}$ and temperature $300 \mathrm{~K}$.

For Japanese tests, the calculation domain is $88 \mathrm{~m}$ diameter hemisphere with a hexahedral mesh of $147,104 \mathrm{CVs}$. It was initialised with pressure $0.101325 \mathrm{MPa}$, temperature $282 \mathrm{~K}$ and air composition. The region corresponding to the tank is initialised with hydrogen mass fraction 1, burst pressure 94.54 $\mathrm{MPa}$ and $99.47 \mathrm{MPa}$ for Tests 1 and 2 respectively. Hydrogen temperature was not measured in tests, it is calculated by Abel-Noble EOS as $376 \mathrm{~K}$ and $397 \mathrm{~K}$ for Tests 1 and 2 respectively.

Numerical initiation of combustion in the simulations with instantaneous removal of a tank wall by the diffusion mechanism is observed [13]. The effect of the Discrete Ordinates radiation model [16] is found to not affect the pressure in the blast wave.

\section{RESULTS AND DISCUSSION}

\subsection{The USA test}

\subsubsection{Convergence by CFL number}

Figure 3a shows the results of simulations convergence exercise by changing the CFL number. The convergence of solution by the amount of burned hydrogen and hydrogen imbalance in the domain is achieved at $\mathrm{CFL} \leq 0.1$. Hydrogen imbalance is calculated as $\left(\left(H_{2}^{\text {Total }}-H_{2}^{\text {Initial }}\right) / H_{2}^{\text {Initial }}\right) \times 100$, where $H_{2}^{\text {Total }}$ is the total mass of hydrogen at time $t$ integrated through the calculation domain and left through the domain boundary. The mass of hydrogen in all species containing hydrogen is integrated: $\mathrm{H}_{2}, \mathrm{H}, \mathrm{H}_{2} \mathrm{O}, \mathrm{HO}_{2}, \mathrm{OH}, \mathrm{H}_{2} \mathrm{O}_{2}$ for 37 reactions chemical mechanism [13] (only $\mathrm{H}_{2}$ and $\mathrm{H}_{2} \mathrm{O}$ for the onestep chemistry); $H_{2}^{\text {Initial }}$ is the amount of hydrogen at the simulation start. The mass of burned hydrogen is calculated as a difference between the initial and current amount of molecular hydrogen in the calculation domain.

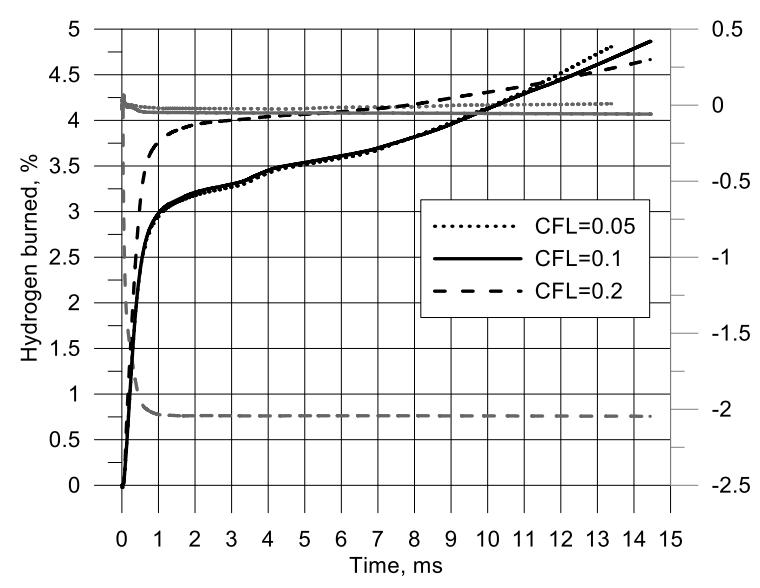

(a)

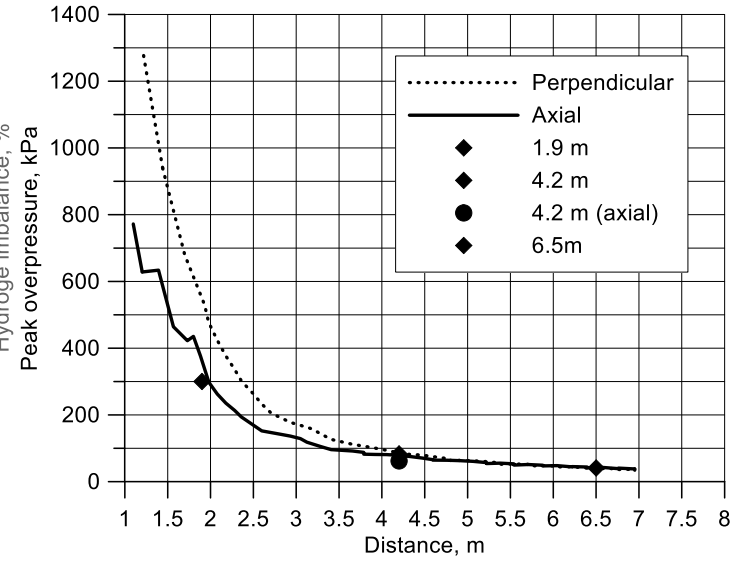

(b)

Figure 3. (a) - burned hydrogen mass (black curves, left $\mathrm{Y}$-axis) and hydrogen imbalance in the calculation domain (grey lines, right Y-axis) as a function of time. (b) - maximum blast wave pressure as a function of distance perpendicular to (dotted line) and along the tank axis (solid line), symbols: test data [6-8].

Further simulations are performed with $\mathrm{CFL}=0.1$. This is below usually accepted for deflagration simulations value $\mathrm{CFL}=0.7$ due to higher shock propagation velocity compared to the speed of sound. The shock wave propagation velocity is $u_{s h}=2165.9 \mathrm{~m} / \mathrm{s}$, while the speed of sound in hydrogen at 
conditions of storage is only $c=1336 \mathrm{~m} / \mathrm{s}$ (ideal gas to account for simulations conditions). Thus, the shock Mach number is $M_{s h}=u_{s h} / c=1.62$.

When the blast reaches the third sensor at $6.5 \mathrm{~m}$ at $t=10.7 \mathrm{~ms}$, the burnt hydrogen amount is $4.3 \%$ (Fig. 3a). This is near to $5.2 \%$ determined for the same experiment using the theoretical model [5]. The rate of combustion drops significantly after $1 \mathrm{~ms}$.

\subsubsection{Effect of tank orientation}

Figure $3 \mathrm{~b}$ shows the maximum blast wave overpressures in the directions perpendicular to and along the tank axis. At the same distance from the tank with a ratio of length to diameter $L: d>1$, a stronger shock wave is always observed in the direction perpendicular to the tank axis. This is due to a more pronounced 3D effect of pressure decay at the tank ends (domes) compared to rather 2D decay on the tank side in the near field. Figure $3 \mathrm{~b}$ demonstrates that the difference for tank $L: d=2: 1$ disappears in the far-field at distances larger than $D>5 \mathrm{~m}$, i.e. when is $D: d>10(d=\sqrt[3]{6 V / \pi}=0.483 \mathrm{~m})$. This is valid for the third pressure sensor location at $6.5 \mathrm{~m}$ only, where $D: d=13.5$. Based on the above, we can conclude that the initial blast wave pressure is higher and thus decays faster in the near field in the direction perpendicular to the tank axis. The directional difference in overpressure at $1.5 \mathrm{~m}$ is about $0.37 \mathrm{MPa}$. In the far-field blast wave pressure does not depend on the propagation direction.

\subsubsection{Pressure discontinuity decay and starting shock}

Figure 4 shows the pressure discontinuity decay during "instantaneous numerical" tank opening into the air for non-reacting and reacting (combustion) cases. When considering the ideal gas EOS for gas in the tank (as in the simulations), the starting shock pressure is calculated as $4.4 \mathrm{MPa}$ using 1D theory. In $3 \mathrm{D}$ simulations without combustion, the early propagation of pressure wave and rarefaction wave (0$70 \mu \mathrm{m}$ ) shows starting shock rapidly decreasing from about 5.5 MPa to below 4 MPa. The starting shock decays with distance faster along the tank axis as expected. In the simulations with combustion the peak of leading shock at distance $0.5 \mathrm{~m}$ is increased due to combustion from $3.8 \mathrm{MPa}$ to $6.0 \mathrm{MPa}$ in the axial direction (from 2.5 MPa to $3.3 \mathrm{MPa}$ in the direction perpendicular to the tank). This proves the contribution of combustion to the blast wave strength.

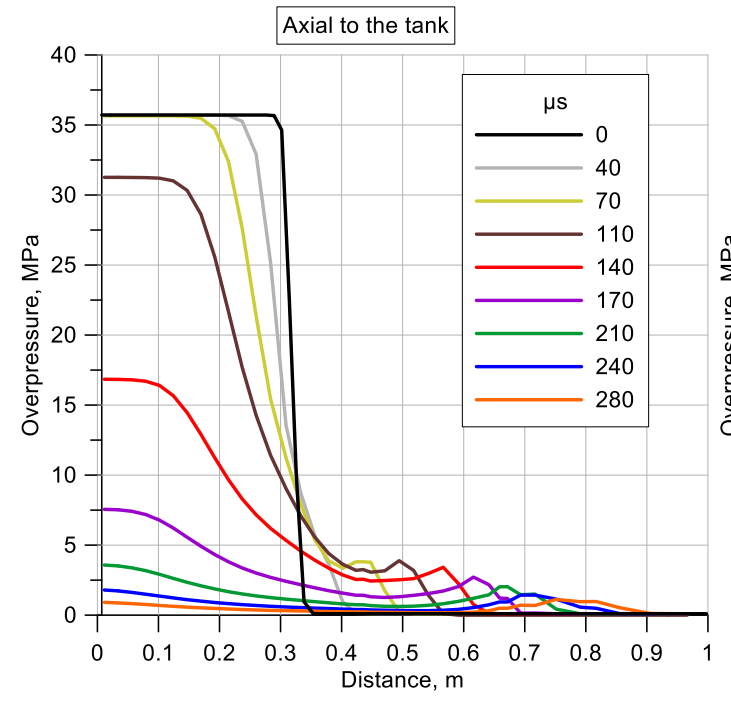

(a)

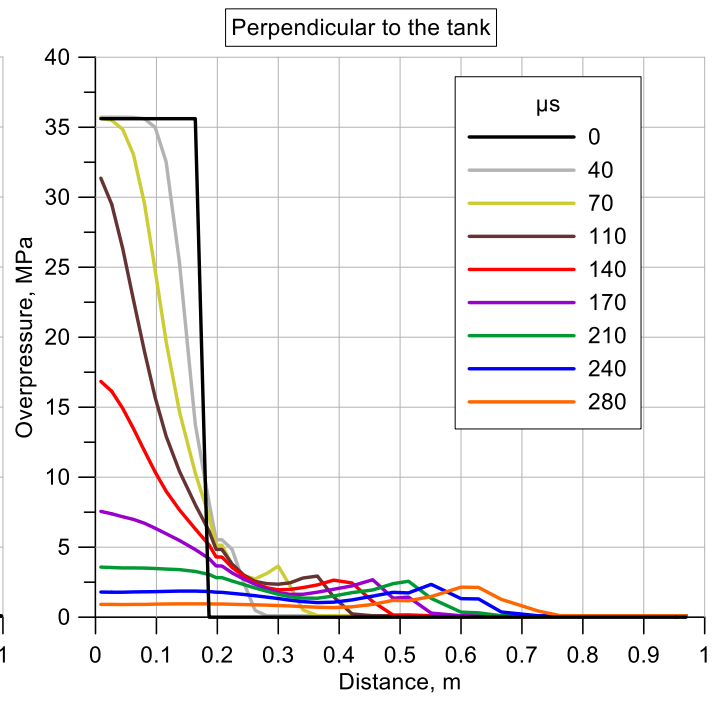

(b) 


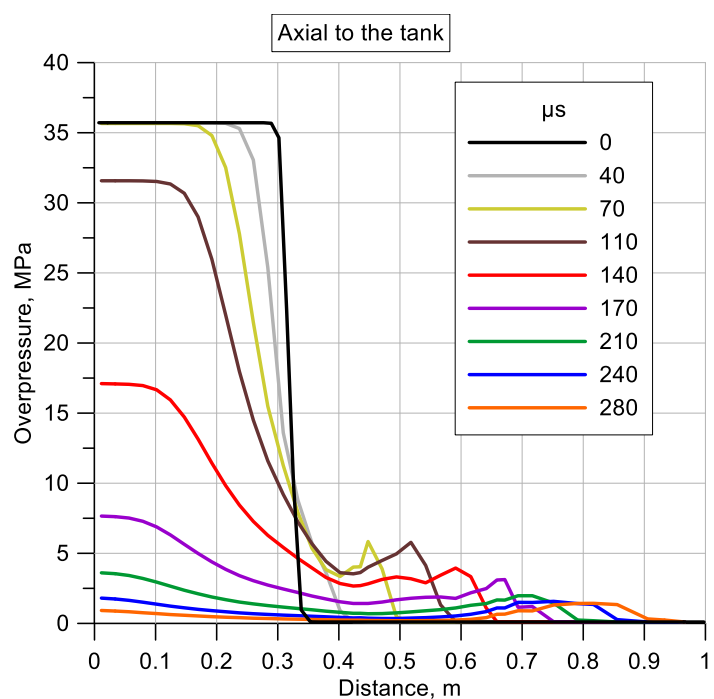

(c)

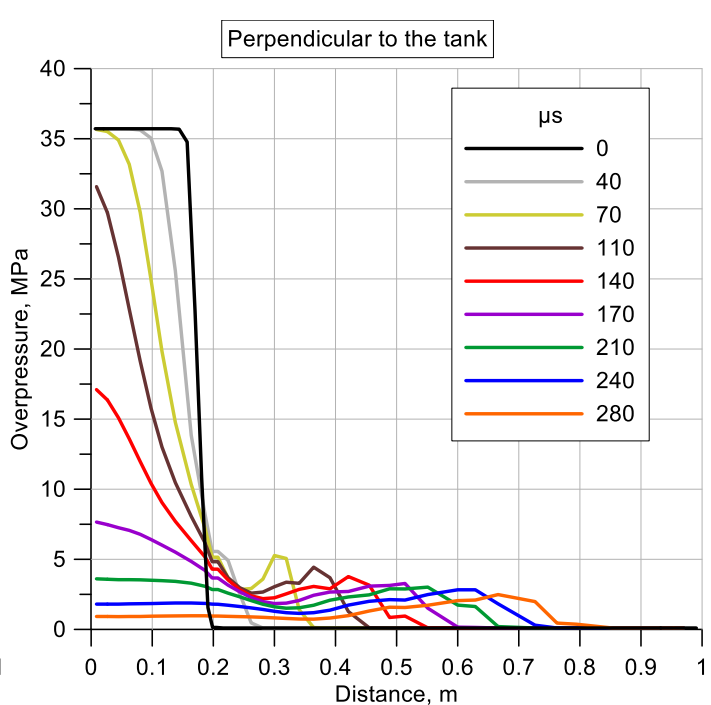

(d)

Figure 4. Pressure discontinuity decay at the tank wall in the direction along the tank axis and perpendicular to the tank axis: (a) and (b) - no combustion at the contact surface, (c) and (d) - with the presence of combustion.

\subsubsection{Pressure dynamics: simulations with combustion versus experiment}

Figure 5 shows the experimental and simulated pressure transients at three sensor locations. The experimental pressure transients do not define when the tank ruptured. They were shifted to match the simulated pressure transients at the first pressure sensor location. Figure 5a shows simulated pressure transients in the direction along the tank axis and Fig. $5 \mathrm{~b}$ in the direction perpendicular to the tank axis (note: experimental pressure transients in both figures are in the direction perpendicular to the tank axis). There is overprediction of the experimental (measured perpendicular to the tank axis) pressure in the simulations in the near field (sensor at $1.9 \mathrm{~m}$ ) with $80 \%$ overprediction for simulations without the burner pan and only $15 \%$ in the presence of the pan. The difference between the simulations and experimental overpressure in the blast wave practically disappears for sensors located at $4.2 \mathrm{~m}$ and 6.5 $\mathrm{m}$ (far-field). This difference in the reproduction of experimental pressure at different locations could be attributed to the fact that simulations are performed in the assumption of instantaneous removal of non-inertial tank walls. The consequences of this assumption are the ignoring of losses of the mechanical energy on projecting tank fragment, the increase of turbulence and area of the contact surface between air and hydrogen by the presence of tank fragments after tank rupture, and thus some "delay" in the initiation of combustion in reality due to these reasons.

The burner pan with dimensions $L \times H \times W=230 \times 81 \times 20 \mathrm{~cm}$ is introduced into the calculation domain. This is realised by introducing four sides of the pan with height $20 \mathrm{~cm}$ and the bottom (placed $3 \mathrm{~cm}$ above the ground) [6]. Figure 5 demonstrates that the presence of the burner pan gives much better agreement between simulations and the experiment. The simulated blast wave peak pressure in the direction perpendicular to the tank axis at $1.9 \mathrm{~m}$ drops significantly from $540 \mathrm{kPa}$ without burner pan (see Fig. 5b) to $350 \mathrm{kPa}$ with the pan. The decrease of overpressure is due to the blast reflection on walls, deflecting some of the pressure upwards. The amplitude and timing of the secondary pressure peak at $1.9 \mathrm{~m}$ (sub-peak on the descending part of the pressure transient) is reproduced better as well. The second and third sensors are nonetheless well fitted with experimental maximum pressures and are not significantly influenced by the pan presence. The simulated front of the shock wave is "smeared" compared to the experimental shock front. There is a numerical requirement that "resolution" of any numerical discontinuity requires 3-5 control volumes (unless special ad-hoc methods are developed and implemented). We did not aim at exact reproduction of shock front by the discontinuity tracking methods that would imply huge additional efforts without guarantee of success. The primary interest 
for hydrogen safety is a reproduction of maximum pressure and impulse decay with distance for assessment of harm to people and damage to structures.

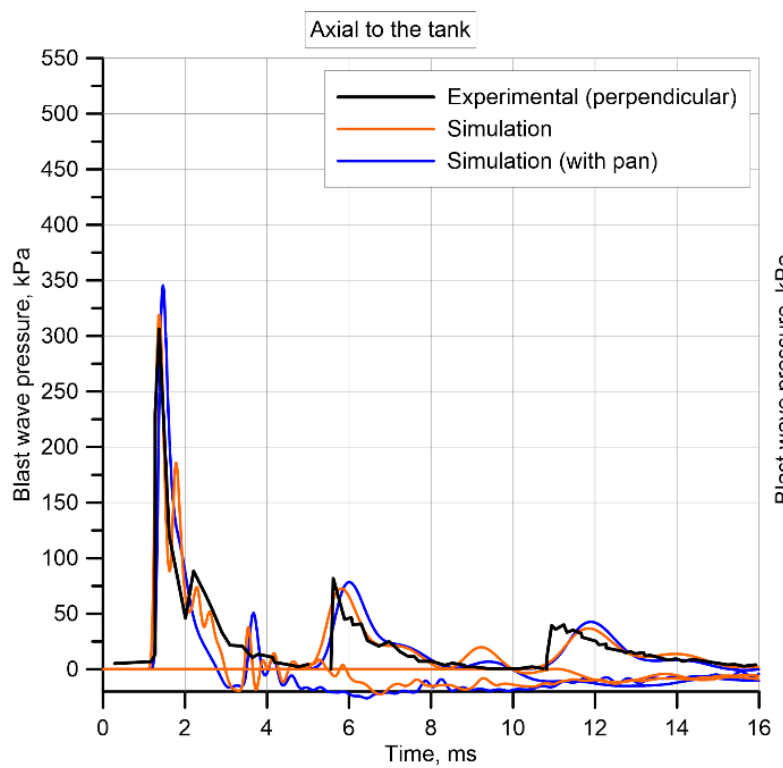

(a)

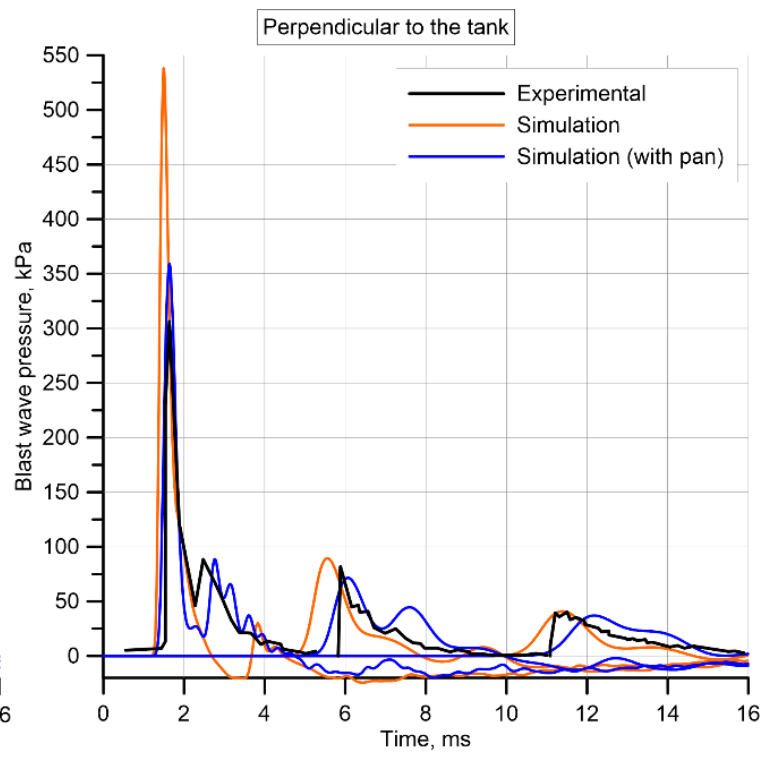

(b)

Figure 5. Experimental pressure transients measured perpendicular to the tank axis. Simulated pressure at the same distances along the tank axis (a), and perpendicular to the tank axis (b), both with and without the pan present.

The propulsion of the tank fragments is not simulated. Quantifying energy losses in connection with non-ideal behaviour and providing fragment kinetic energy is found to be predicted diversely, in the range up to $20-60 \%$ [16-18]. The propulsion of fragments in the experiment consumes a part of the mechanical energy and "equalises" both directions in the sense of maximum pressure. Indeed, Fig. 5a shows that numerical pressure at $1.9 \mathrm{~m}$ in the direction along the tank axis is practically equal to experimental pressure at $1.9 \mathrm{~m}$ in the direction perpendicular to the tank. The fact that the blast wave pressure dynamics is reproduced reasonably in the far-field demonstrates that the sum of mechanical energy of compressed gas and fraction of chemical energy released during combustion and contributed to the blast wave are reproduced quite well by the CFD model. The overprediction of pressure in the near field could be explained by a faster release of chemical energy (combustion) in simulations immediately after the tank rupture before the blast wave reached sensor at $1.9 \mathrm{~m}$ (at $1.2 \mathrm{~ms}$ ), i.e. because of the faster reaction at the immediately available in simulations contact surface when the pressure of starting shock is still at its maximum. In reality, the fragments could "reduce" area of the contact surface and thus reduce the release of chemical energy immediately after the inertial (real) tank walls opening. From another point of view, the tank fragments increase turbulence mixing and thus could increase reaction rate a bit later. These two "effects" of the wall fragments compensate each other to reproduce experimentally observed pressure quite accurately at locations of the second and the third sensors.

\subsection{5. "Fire plume" effect}

Previous simulations are carried out with numerical initiation of combustion by the diffusion mechanism of spontaneous ignition of a sudden release of hydrogen in the air [13]. However, in the experiment, a fire and high-temperature plume are raising above the burner with a different composition from the surrounding air. This would exclude hydrogen combustion at the contact surface with combustion products at the start when hydrogen combustion is the most intensive (see Fig. 3a).

Let us imitate "fire plume" in simulations as follows (no burner pan is present in the calculation domain). The reaction of complete combustion of propane from the burner in air is: $\mathrm{C}_{3} \mathrm{H}_{8}+5 \mathrm{O}_{2}+5$. $3.76 \mathrm{~N}_{2} \rightarrow 3 \mathrm{CO}_{2}+4 \mathrm{H}_{2} \mathrm{O}+5 \cdot 3.76 \mathrm{~N}_{2}$. The number of moles generated by the combustion of one mole of propane in the air is considered. The mass fraction of water vapour in the combustion products can be calculated as 0.1 , with remaining species attained as nitrogen with mass fraction 0.9 . The "fire 
plume" patch area is therefore considered to be filled with combustion products at temperature $900 \mathrm{~K}$. The measured flame temperature in the diffusive combustion propane burner was $1300 \mathrm{~K}$. Two hexahedral mesh patches are tested. The small patch of size $L \times H \times W=2.3 \times 1.3 \times 0.8 \mathrm{~m}\left(2.4 \mathrm{~m}^{3}\right)$ replicates the test burner pan. The patch encases the cylinder and propane burner up. The big patch of $L \times H \times W=3.9 \times 2.1 \times 1.4 \mathrm{~m}$ (almost five times bigger volume of $11.5 \mathrm{~m}^{3}$ ) aims at imitating a real fire size.

Figure 6a demonstrates that the start of hydrogen combustion is delayed with a patch present as expected. The delay increases with patch size. There is no combustion at the contact surface between hydrogen and combustion products.

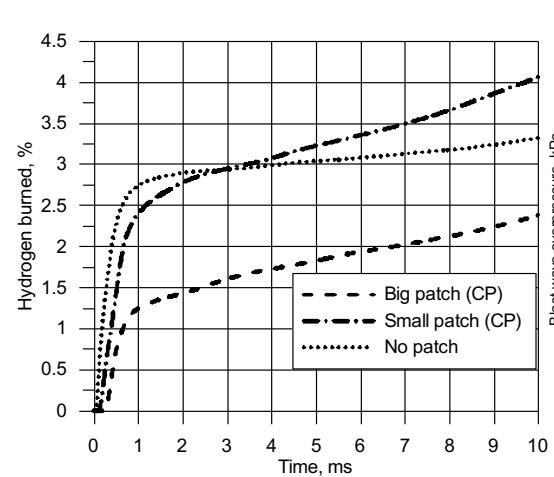

(a)

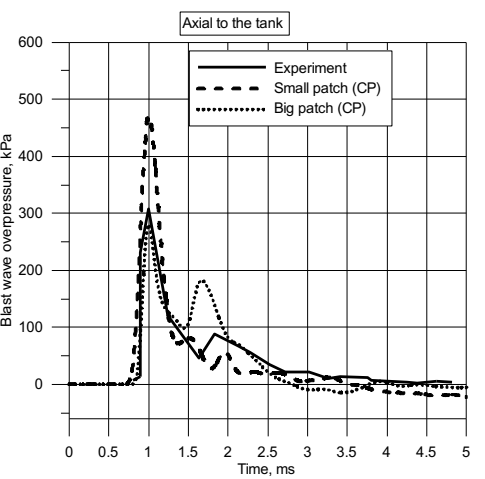

(b)

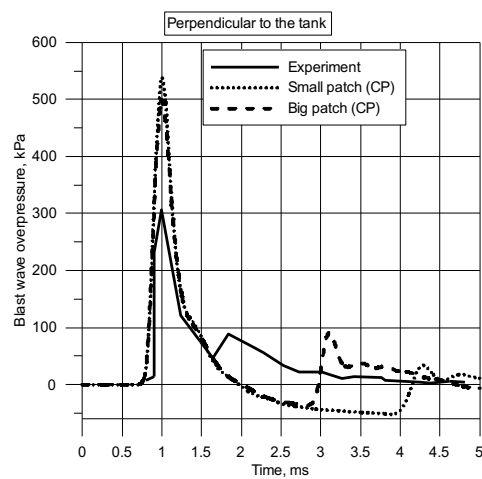

(c)

Figure 6. Hydrogen burned mass for two combustion products (CP) patches as a function of time (a).

Pressure dynamics at $1.9 \mathrm{~m}$ : axial (b) and perpendicular (c) to the tank axis direction. Note:

experimental pressure transients are for the direction perpendicular to the tank axis for both graphs.

Figures $6 \mathrm{~b}$ and $6 \mathrm{c}$ show that a patch size essentially changes the pressure dynamics. Perpendicular to the tank axis, a little difference is seen. Contrarily, axially to the tank, the peak pressures are considerably different. For the big patch, the first peak is even lower than measured in the experiment. A reason is as follows. The big patch size in the axial direction is $1.95 \mathrm{~m}$ from the tank. Thus, the first pressure sensor location $(1.9 \mathrm{~m})$ is within the patch. Thus, the "artificial" exclusion of combustion in simulations until the first sensor in the axial direction unsurprisingly reduces the peak below the experimental one.

Presence of a small rectangular patch affects the fireball dynamics to some extent. Indeed, there is no combustion seen within the patch (Fig. 7, snapshots $0.2 \mathrm{~ms}$ ). The temperature of hydrogen drops significantly due to expansion. As soon as hydrogen expands beyond the area of the combustion products patch (Fig. 7, snapshots $0.6 \mathrm{~ms}$ ), the reaction between hydrogen and air is manifested by the increase of temperature at the contact surface (accompanied by water generation). The blast wave pressure decays with distance (Fig. 7, snapshots $3 \mathrm{~ms}$ ).

\begin{tabular}{|c|c|c|c|c|c|}
\hline & $\begin{array}{c}\text { Pressure, } \mathrm{kPa} \\
\text { Range: } 101-906\end{array}$ & $\begin{array}{l}\text { Temperature, } \mathrm{K} \\
\text { Range: } 62-1930\end{array}$ & $\begin{array}{l}\text { Mole fraction } \mathrm{H}_{2} \\
\text { Range: } 0-1\end{array}$ & $\begin{array}{c}\text { Reaction rate } \mathrm{H}_{2} \mathrm{O}, \\
\mathrm{kg} / \mathrm{m}^{3} \mathrm{~s} \\
\text { Range: } 0-31200\end{array}$ & $\begin{array}{c}\text { Mole fraction } \mathrm{H}_{2} \mathrm{O} \\
\text { Range: } 0-0.3\end{array}$ \\
\hline & Pressure & Tamperaver & 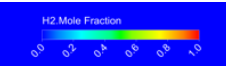 & 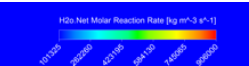 & 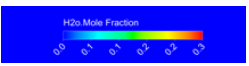 \\
\hline $\begin{array}{l}\text { בै } \\
\text { กै }\end{array}$ & & & & & \\
\hline
\end{tabular}




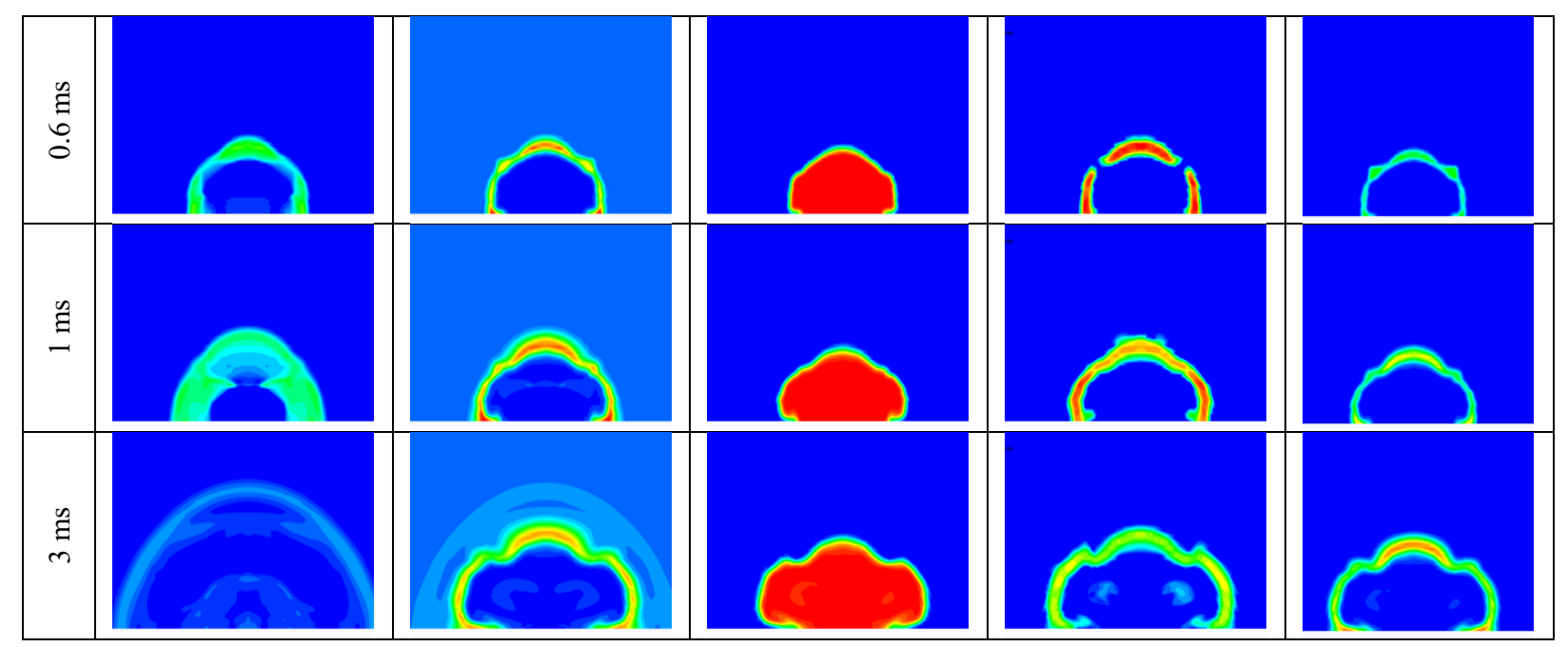

Figure 7. Dynamics of pressure, temperature, hydrogen mole fraction, water production reaction rate and water mole fraction for time $0.2-3 \mathrm{~ms}$ (cross-section perpendicular to the tank axis). Small rectangular patch: $L \times H \times W=2.3 \times 1.3 \times 0.8 \mathrm{~m}\left(2.4 \mathrm{~m}^{3}\right)$.

\subsubsection{The mechanism of combustion contribution to the blast wave}

Let us analyse hydrogen combustion dynamics at the contact surface using Fig. 3 and Fig. 8 together. Figure 3 shows that the reaction rate of hydrogen combustion at the contact surface is high at the start and then drastically reduces at a time between $0.5 \mathrm{~ms}$ and $2 \mathrm{~ms}$. The reaction rate is proportional to the molar concentration of hydrogen $\left[\mathrm{H}_{2}\right]$ and oxygen $\left[\mathrm{O}_{2}\right]$. The dilution of the reaction zone at the contact surface by combustion products (water vapour) reduces the concentrations of the reactants. However, the main reason for the reduction of reaction rate is the drastic decrease in pressure in the reaction zone as a starting shock pressure decays with distance. A species molar concentration is proportional to the partial pressure of the species, i.e. $\left[\mathrm{H}_{2}\right]=p_{\mathrm{H}_{2}} / R T$. With two reactant species, it is expected that the reaction rate varies as $p^{2}$ based on the global reaction rate proportional to $r \times\left[\mathrm{H}_{2}\right]^{1} \times\left[\mathrm{O}_{2}\right]^{1}[19]$. The reaction rate constant is defined by the Arrhenius equation as $r=A \cdot \exp \left(-E_{a} / R T\right)$.

Figure 8 presents a spatial distribution (perpendicular to the tank axis) of combustion reactants $\left(\mathrm{H}_{2}\right.$ and $\mathrm{O}_{2}$ ), combustion products (diluent $\mathrm{H}_{2} \mathrm{O}$ ), plotted together with the pressure and the reaction rate of water production for period 0.1-3.0 ms when the drastic decrease of combustion rate is observed. The graphs demonstrate that the pressure at the contact surface, which can be identified as the location of the maximum rate of water vapour production and higher temperature, is strongly decreasing by two orders of magnitude from about $10 \mathrm{MPa}$ at $0.1 \mathrm{~ms}$ to practically atmospheric pressure $(0.1 \mathrm{MPa})$ at $3.0 \mathrm{~ms}$. The reaction rate reduces by almost three orders of magnitude (500 times). The relative concentration of water vapour at the contact surface is increasing but not as much to explain the reaction rate drop. The contact surface moves outwards following the leading shock but with lower velocity. The distance between the leading shock and the contact surface increases with time (see Fig. 7 as well). 

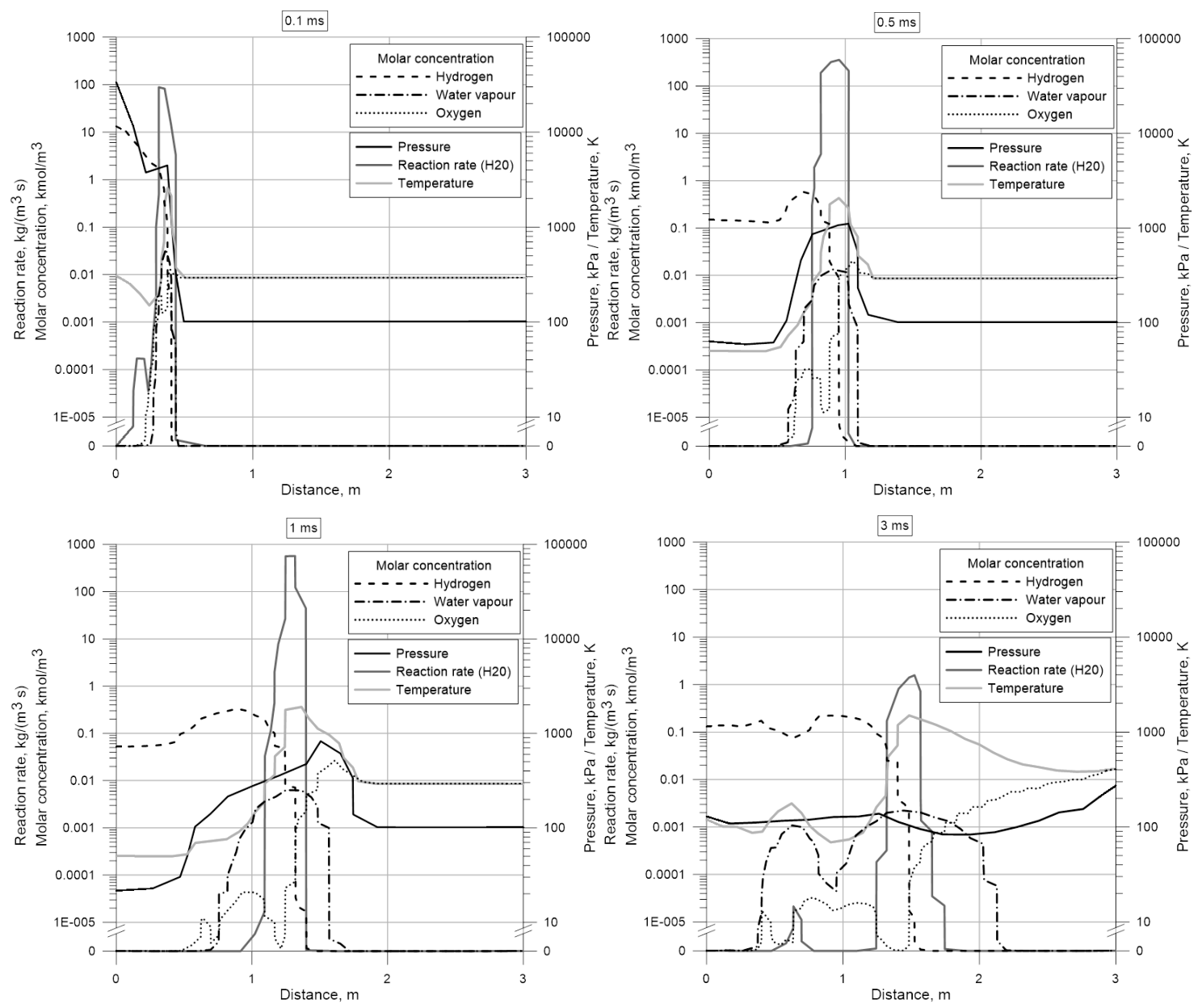

Figure 8. Molar concentrations of $\mathrm{H}_{2}, \mathrm{H}_{2} \mathrm{O}, \mathrm{O}_{2}$, pressure, temperature and reaction rate of water vapour generation along the distance perpendicular to the tank axis at time $0.1,0.5,1.0$, and $3.0 \mathrm{~ms}$.

\subsubsection{Fireball dynamics}

To assist in the understanding of the fireball size dynamics at the initial stage, Fig. 9a shows changing in time the height and width of the simulated fireball taken from different directions (perpendicular, axial and diagonal to the tank) during the first $100 \mathrm{~ms}$. The size of the fireball is determined by the minimum temperature of $363 \mathrm{~K}\left(70^{\circ} \mathrm{C}\right)$ accepted as a no-harm limit for humans. The average through three different directions simulated diameter is about $7.9 \mathrm{~m}$ at $45 \mathrm{~ms}$ (vertical dash line in Fig. 9a). The experimentally observed fireball diameter at $45 \mathrm{~ms}$ was $7.7 \mathrm{~m}$. The comparison of fireball height and width demonstrates that it has a rather hemispherical then spherical shape.

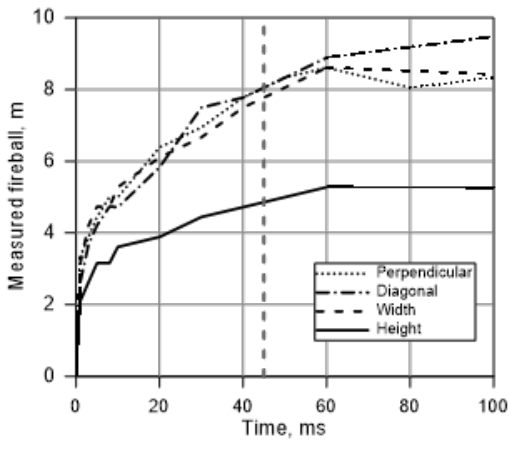

(a)

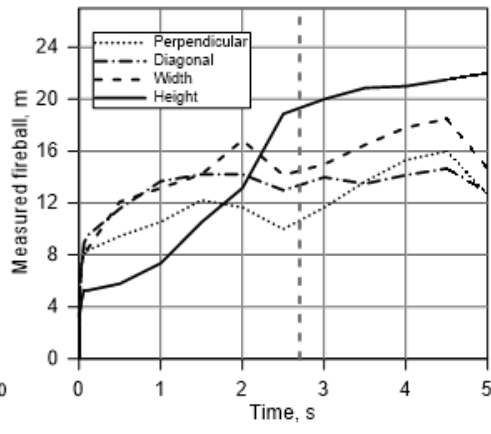

(b)

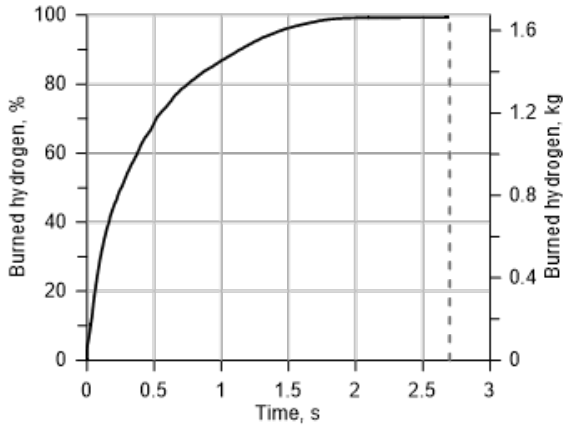

(c) 
Figure 9. Simulated fireball height and horizontal size (perpendicular, axial, and diagonal to the tank axis) as a function of time. (a) - 0-100 ms, (b) - 0-5 s. (c) - the hydrogen burned until reaction completion. Simulations with the burner pan and a fire patch.

Figure $9 \mathrm{~b}$ illustrates the fireball size dynamics extended until $5 \mathrm{~s}$, after which the fireball maximum temperature dropped below the no-harm temperature threshold of $363 \mathrm{~K}\left(70^{\circ} \mathrm{C}\right)$ throughout the domain. The threshold $363 \mathrm{k}\left(70^{\circ} \mathrm{C}\right)$ is chosen for visualisation of fireball by the following reasoning. It is the "no-harm" temperature for humans and thus simulation snapshots present hazard distance defined by temperature. Figure 10 demonstrates that the temperature on the fireball boundary changes from ambient to the highest temperature of combustion products in a very short distance compared to the fireball size. Thus, the choice of the temperature boundary for fireball visualisation does not affect the simulated fireball size. The fireball reaches $22 \mathrm{~m}$ height at $5 \mathrm{~s}$. This can be considered as "no-harm" hazard distance by temperature in a vertical direction. The horizontal size of the "thermic" at this moment is below $15 \mathrm{~m}$. It is worth mentioning that these "no-harm" by temperature distances would be well inside the hazard distance defined by projectiles such as tank fragments, etc. The hazardous effect of tank fragment is out of the scope of this study.

The vertical dash line in Fig. 9b and graph in Fig. 9c show when the combustion ceases at $2.7 \mathrm{~s}$ (no further generation of $\mathrm{H}_{2} \mathrm{O}$ ). Thus, the fireball cools down to not harmful temperature in $2.3 \mathrm{~s}$. Noticeable, the lifetime of hydrogen combustion $(2.7 \mathrm{~s})$ is almost half of the total fireball duration.

Figure $9 \mathrm{c}$ presents the burned hydrogen towards its almost complete depletion (99.4\%). The remaining $0.6 \%$ of hydrogen is mixed with air and water below the lower flammability limit, thus remaining unreacted in the domain.

Figure 10 shows the fireball dynamics at time $10-100 \mathrm{~ms}$ for simulations both with the pan and small patch. The fireball dynamics is affected by dilution of hydrogen by combustion products (water) while oxygen pockets just start to penetrate inside the hydrogen cloud. Contours of mole fractions of hydrogen and oxygen demonstrate the development of swirls that increases the contact surface.

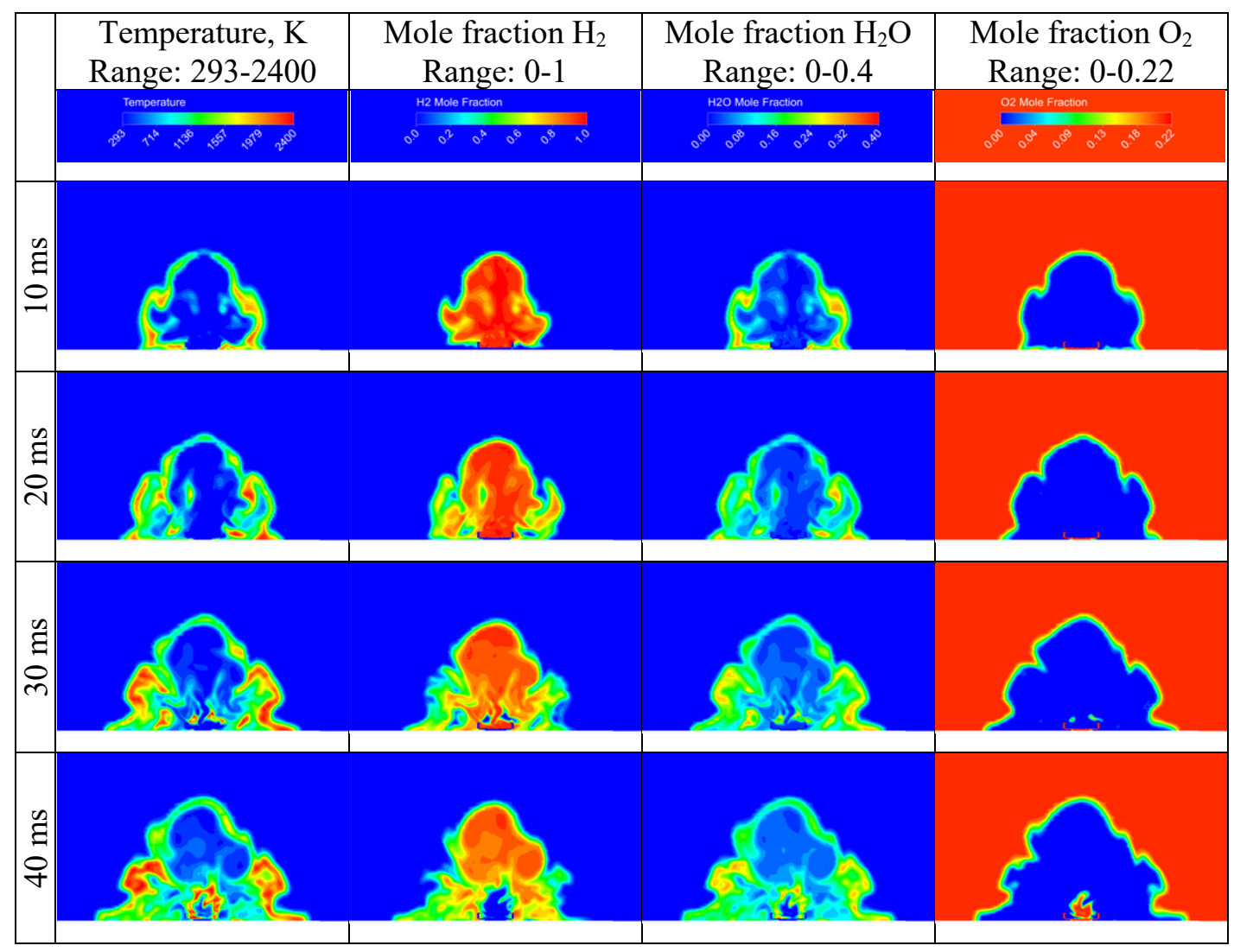




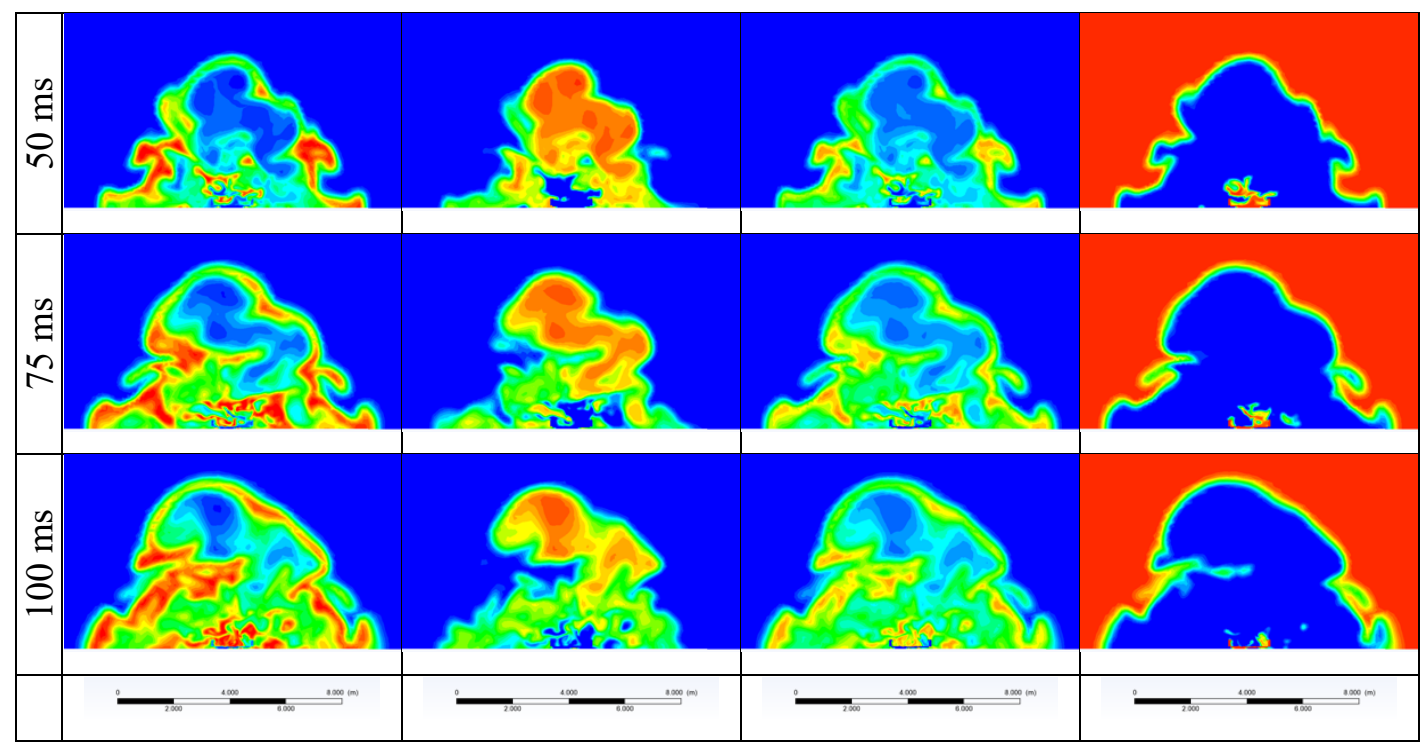

Figure 10. Fireball dynamics (temperature, mole fractions of $\mathrm{H}_{2}, \mathrm{H}_{2} \mathrm{O}$ and $\mathrm{O}_{2}$ ) at 10-100 ms captured at a 45-degree angle to the tank axis (as in the test). Simulations with the pan and small patch.

\subsection{Japanese tests}

The CFL sensitivity exercise is performed to assure the solution convergence with a variation of CFL from 0.02 to 2. Figure 11a shows pressure transients variation when changing CFL from 0.02 to 0.60. $\mathrm{CFL}=2$ provided $10 \%$ higher overpressure peak at $2 \mathrm{~ms}$ (not shown in Fig. 11). The alteration between simulations with different CFL number decreases with time. The difference becomes negligible when the blast wave reaches the sensor at $5 \mathrm{~m}$.

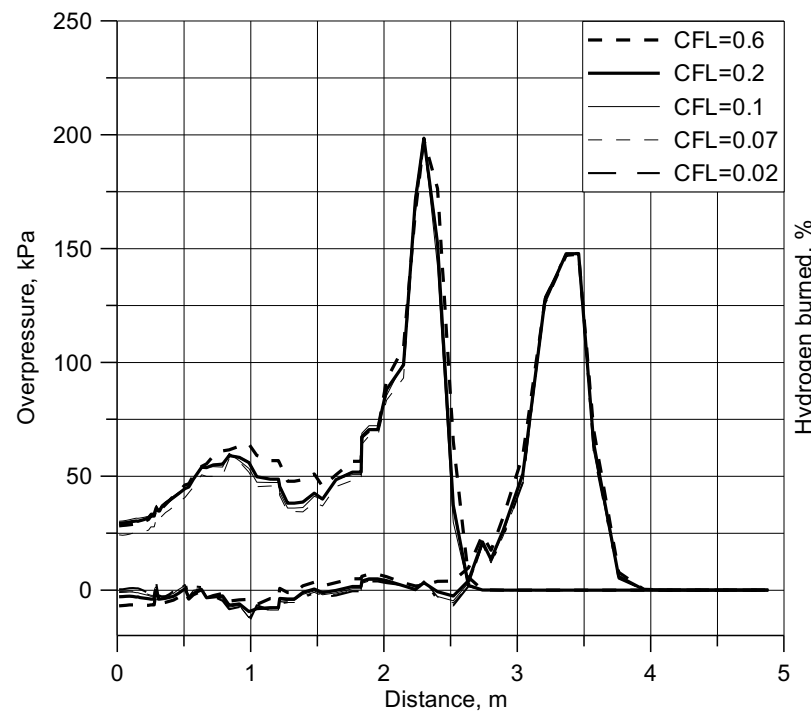

(a)

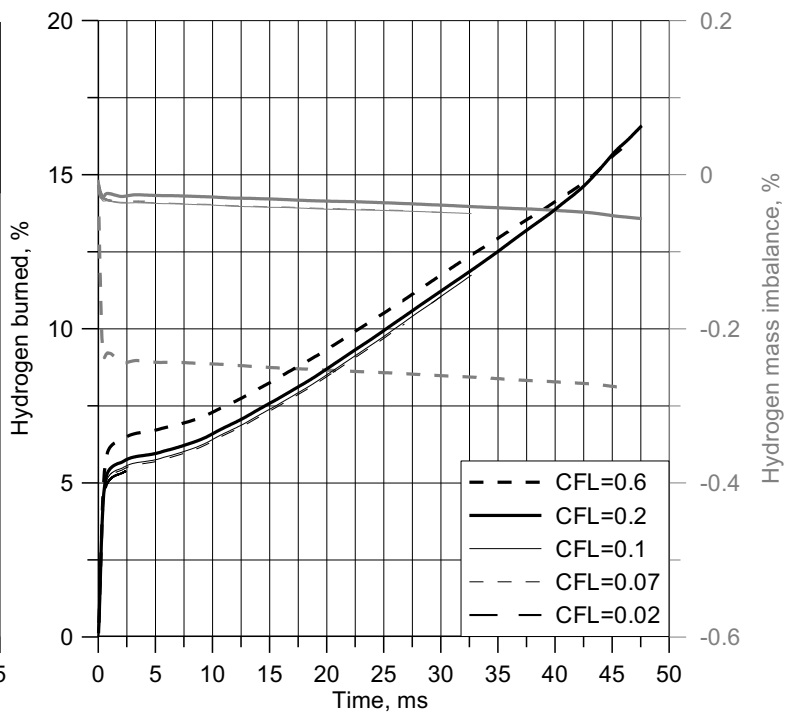

(b)

Figure 11. The CFL sensitivity exercise (Test 1). (a) - pressure distribution in the direction perpendicular to the tank axis at $2 \mathrm{~ms}$ and $4 \mathrm{~ms}$, (b) - the amount of burned hydrogen and imbalance of hydrogen in the domain as a function of time. The FRC and RNG sub-models.

Figure $11 \mathrm{~b}$ shows changes in the amount of burned hydrogen and imbalance of hydrogen in the calculation domain for $\mathrm{CFL}=0.02-0.60$. The difference in burned hydrogen decreases with time, e.g. at $42 \mathrm{~ms}$ the amount of burned hydrogen is the same for $\mathrm{CFL}=0.6$ and $\mathrm{CFL}=0.2$. Hydrogen mass imbalance increases with CFL number but remains below $0.5 \%$. The $C F L=0.2$ is applied to reduce simulations time by the factor of two while maintaining a reasonable accuracy in simulations of pressure dynamics for the parametric studies reported in the following sections. Figure $11 \mathrm{~b}$ shows that $5-6 \%$ of hydrogen 
mass burns at significantly higher reaction rate within $1 \mathrm{~ms}$. The much slower combustion afterwards requires $25 \mathrm{~ms}$ to burn another $5 \%$ of hydrogen. There is a slight increase in the combustion rate during the "slower" combustion phase. This is due to the growth of the contact surface area in time including due to flow instabilities. When the blast wave reaches the sensor at $10 \mathrm{~m}, 8.7 \%$ of hydrogen is burnt. Simulation of $50 \mathrm{~ms}$ (Test 1) required approximately 44 hours on a 32 processors workstation. Timestep with the use of $\mathrm{UDF}$ with constant $\mathrm{CFL}=0.2$ increases during the simulations by almost 3.3 times from $1.8 \cdot 10^{-6}$ to $5.9 \cdot 10^{-6} \mathrm{~s}$.

The solution provided by the adapting time step technique (constant CFL) is compared to the solution obtained keeping a constant time step. The starting shock velocity in the air for hydrogen storage pressure $94.5 \mathrm{MPa}$ and temperature $380 \mathrm{~K}$ (Test 1) is $2729 \mathrm{~m} / \mathrm{s}$ assuming the equation of speed of sound for an ideal gas, and the speed of sound in hydrogen is $1481 \mathrm{~m} / \mathrm{s}$. If the real gas equation is used then the starting shock velocity increases to $3394 \mathrm{~m} / \mathrm{s}$ and the speed of sound in hydrogen to $2171 \mathrm{~m} / \mathrm{s}$. The minimum CV size is $2 \mathrm{~cm}$ in these simulations, thus a time step equal to $10^{-6} \mathrm{~s}$ is imposed to have CFL below 0.2 . A further case with half of the time step is considered $\left(5 \cdot 10^{-7} \mathrm{~s}\right)$, to assure the independence of the solution. Results showed no difference. However, the implementation of the adapting time step procedure improves the hydrogen mass balance by more than an order of magnitude (from $-0.6 \%$ to $0.03 \%$ at $20 \mathrm{~ms}$ ). Furthermore, the progressive increase of the adapted time steps shortened the calculation time significantly: $\mathrm{CFL}=0.2$ required $44 \mathrm{~h}$ to simulate $50 \mathrm{~ms}$, simulations with constant time step $=10^{-6} \mathrm{~s}$ during the same CPU time calculate only $15 \mathrm{~ms}$ of real-time.

Figure 12 demonstrates the simulations results of the pressure discontinuity decay for NWP $=70 \mathrm{MPa}$ tank (Test 2) without (a,b) and with combustion (c,d). The tank wall is instantaneously removed at $t=0$, producing the starting shock propagating outwards and rarefaction wave propagating inwards. The results agree with the observations on directional effects of cylindrical vessels burst in the simulations of the USA test and study [20] on vessel pressure burst directional effects, where the authors defined the near field as $z<1$, where a scaled stand-off distance is $z=r\left(P_{a m b} / E_{m e c h}\right)^{1 / 3}$, and $r$ is the distance from the tank.

In the near field, the pressure on a side of the tank is higher than the pressure recorded along the cylinder axis. The simulated shock front of the Japanese tests presents a somewhat different shape when compared to the USA test. The USA test (see Fig. 4) shows higher and more pronounced pressure peaks in simulations with combustion $(70-100 \mu \mathrm{s})$. The authors assume that in the Japanese tests combustion has less time to contribute to the maximum pressure compared to the USA test during this period, given the higher shock speeds resulting from the higher storage pressure before the tank rupture. Plus, the reaction rate is higher due to higher pressure in the starting shock and thus at the contact surface. This could affect the zone where negative temperature gradient changes to the positive gradient (the location where acoustic waves from reaction zone stop propagation to the leading shock front and thus feeding the increase of the leading shock pressure by the release of chemical energy during combustion behind the shock wave).
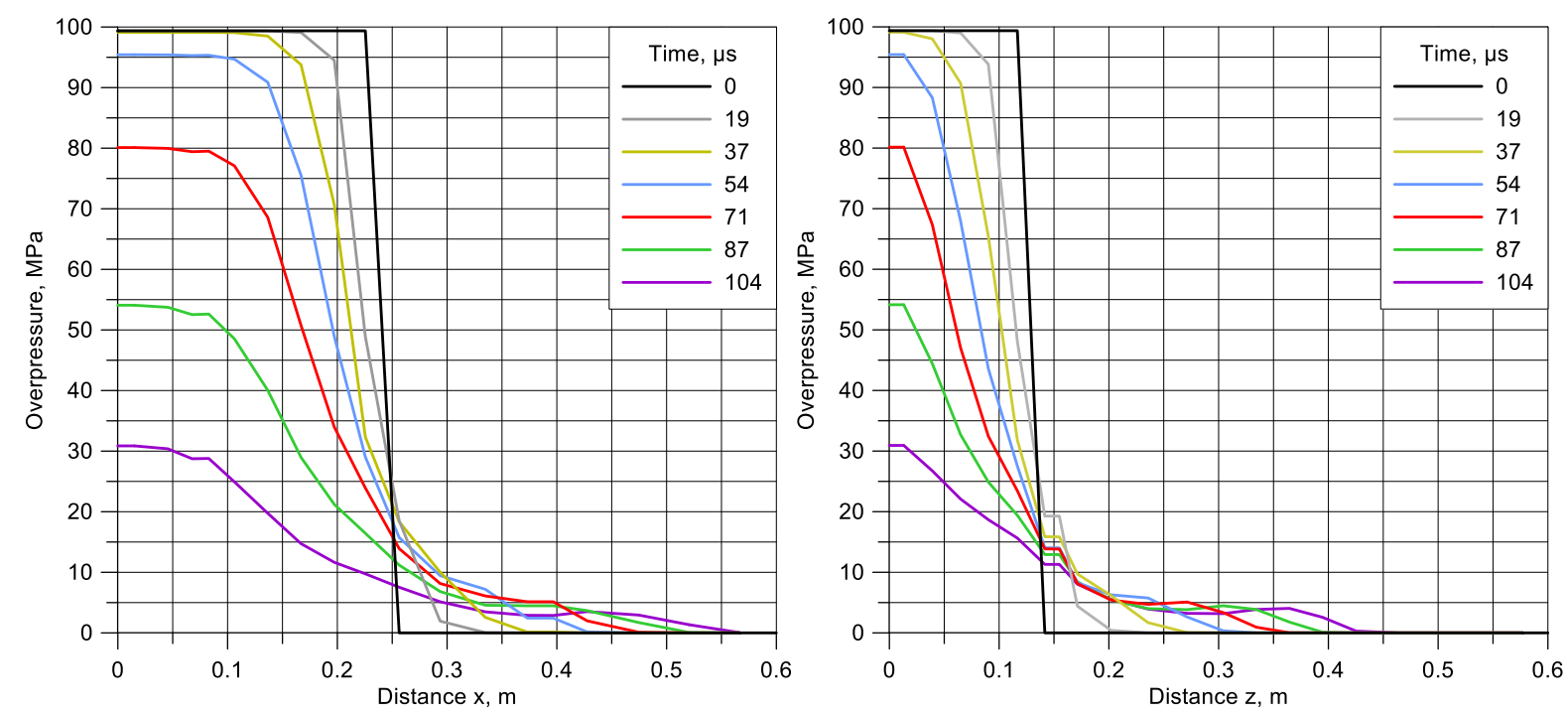
(a)

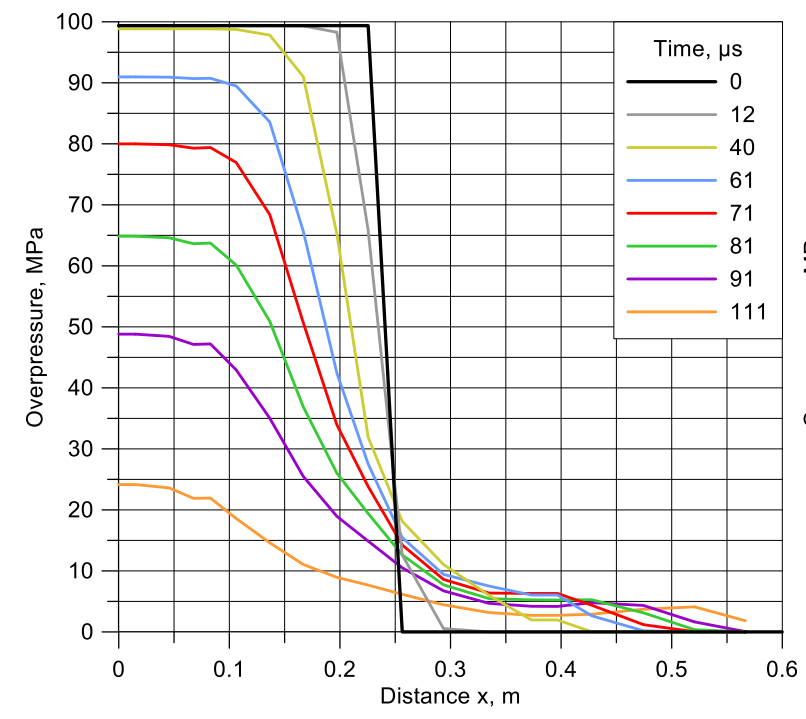

(c) (b)

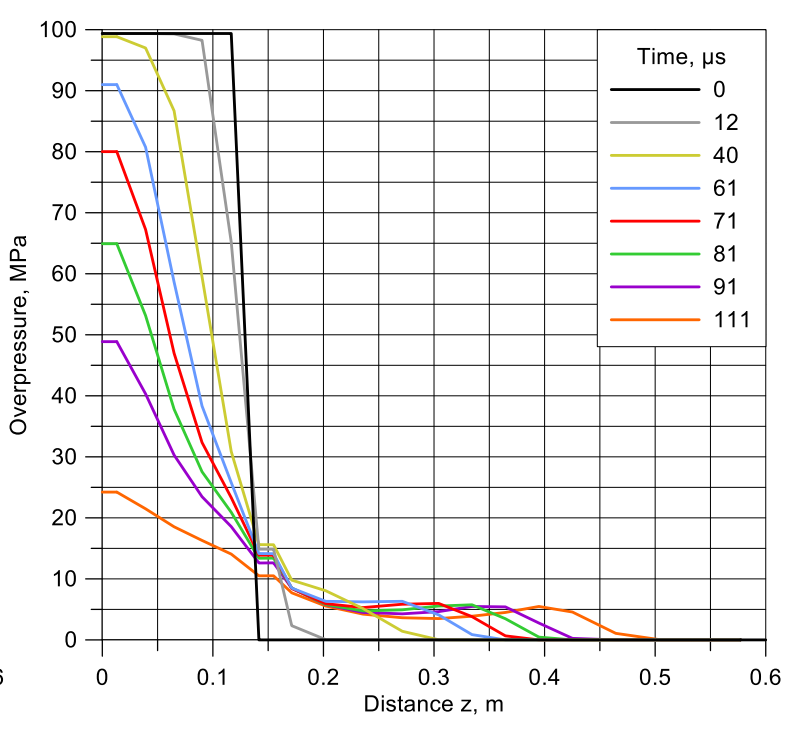

(d)

Figure 12. Pressure discontinuity decay at the tank wall in the direction along the tank axis (distance $x$ ) and perpendicular to the tank axis (distance $z$ ) for Test 2. (a) and (b) - no combustion at the contact surface, 0-104 ms; (c) and (d) - with the presence of combustion, 0-111 ms. The FRC and RNG submodels.

Because of the 2D and 3D character of the blast wave decay at the side and the dome parts of the tank respectively (this is valid for both the USA and the Japanese tests), and due to the uncertainty introduced by a numerical requirement to have 3-5 CVs for any physical discontinuity (here the discontinuities are the shock front and the contact surface), it is impossible to reproduce in 3D simulations a theoretical value of 1D starting shock pressure calculated as $7.50 \mathrm{MPa}$ and $7.86 \mathrm{MPa}$ for Test 1 and 2 respectively. Expectedly, theoretical 1D values are somewhat higher the simulated values of $7.0 \mathrm{MPa}$ and $6.5 \mathrm{MPa}$ for Test 1 and 2 respectively. The simulated shock velocity for Test 2 is approximately $2500 \mathrm{~m} / \mathrm{s}$ at 110 $\mu \mathrm{s}$, which is about $10 \%$ below the theoretical $1 \mathrm{D}$ value of $2793 \mathrm{~m} / \mathrm{s}$. The switching off combustion in simulations causes a decrease of the starting shock pressure from 6.5 MPa to 5.0 $\mathrm{MPa}$ in Test 2, along with a slowdown of the shock propagation velocity to $1750 \mathrm{~m} / \mathrm{s}$ at $104 \mu$ s (Fig. 12).

Figure 13 shows the comparison between the experimental and simulated pressure transients for Tests 1 and 2. Simulations with the instantaneous opening of the entire tank wall reproduce experimental pressure dynamics at both $5 \mathrm{~m}$ and $10 \mathrm{~m}$ for Test 2 (Fig. 13b) with high accuracy. However, for Test 1 there is an underestimation of the experimental pressure peak at $5 \mathrm{~m}$ and the exact reproduction of pressure peak at $10 \mathrm{~m}$ for the instantaneous opening of the tank (Fig. 13a). Negative pressure phase is reproduced in time and magnitude with somewhat higher amplitude for Test 2 . There are numerical oscillations in simulations at later stages of the process. They could be attributed to multiple reflections and shock interactions in simulations while in the experiment they are suppressed by inelastic boundaries, e.g. ground, moving burner pan, etc. It is worth noting that for the finer grid the pressure oscillations have smaller amplitudes and thus numerical reasons cannot be ruled out. 


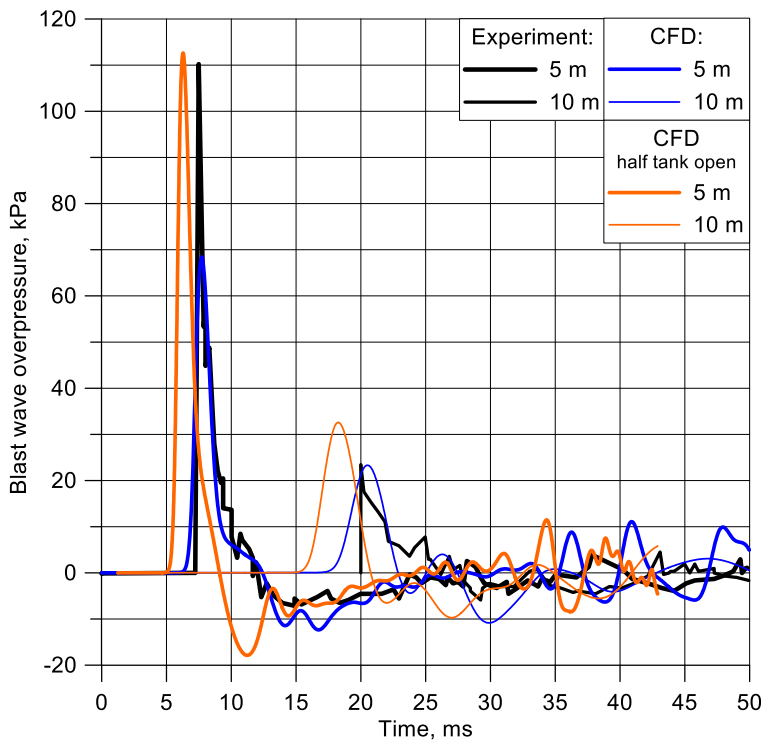

(a)

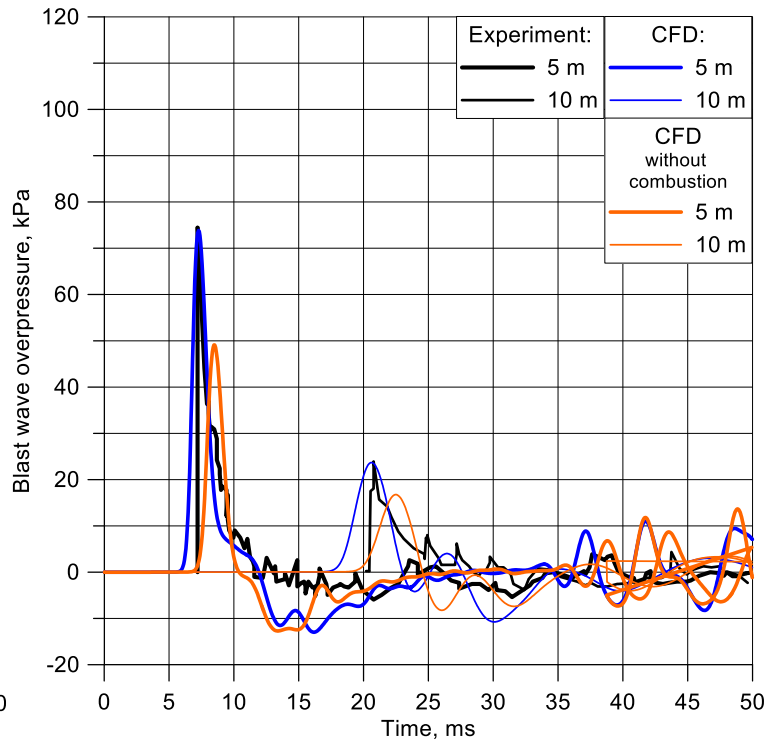

(b)

Figure 13. Simulated versus experimental pressure dynamics perpendicular to the tank axis at $5 \mathrm{~m}$ (thick curves) and $10 \mathrm{~m}$ (thin curves). (a) -Test 1, including the effect of a delayed half tank opening (dashed lines). (b) - Test 2, including simulations without combustion. The FRC and RNG submodels.

Tests 1 and 2 have similar initial experimental conditions. As expected, combustion in simulations proceeds similarly, resulting in comparable pressure dynamics. However, the higher experimental pressure peak at $5 \mathrm{~m}$ in Test 1 indicates that physical processes affecting the pressure dynamics are different in these two tests. This is considered in detail in section 4.2 .2 by evaluation of how the delayed opening of half of the tank wall affects pressure and fireball dynamics.

The effects of the burner pan presence and the surrounding fire were assessed. It is found that the pressure dynamics at sensors locations is not significantly affected, whereas the burnt hydrogen amount increased by $+1.3 \%$ at $22 \mathrm{~ms}$, increasing from $9.2 \%$ to $10.5 \%$ with the burner presence.

\subsubsection{Effect of tank wall "segmentation"}

To get insights into the effect of instantaneous tank wall opening, simulations with a segmented (partially opened) wall are carried out for Test 1 . Figure 14a shows tanks with finer (top) and coarser (bottom) grids. The minimum CV size close to the tank surface was $1.5-2.0 \mathrm{~cm}$ for the finer grid and $3.0-4.0 \mathrm{~cm}$ for the courser grid. White segments are open parts and grey segments are closed parts of the tank surface. The segmented tank is expected to generate more turbulence compared to the case of instantaneous opening of the entire tank wall and affect the contact surface shape. This could increase combustion contribution to the blast wave strength.

In this section, the numerical model encompasses the Explicit Density-Based solver of Fluent version 16.2, LES RNG for SGS turbulence, the FRC sub-model (either 1 or 37 reactions). Table 1 compares the CPU calculation rate (64 cores) for studied cases.

Table 1. Comparison of CPU calculation rate for two grids and two chemistry models.

\begin{tabular}{|l|l|l|l|}
\hline Mesh & Minimum CV size, cm & The FRC model & CPU rate, $\mathbf{m s} / \mathbf{h}$ \\
\hline 450,960 CVs (finer segments) & $1.5-2.0$ & 1 reaction & 0.25 \\
\hline 450,960 CVs (finer segments) & $1.5-2.0$ & 37 reactions & 0.0625 \\
\hline 113,696 CVs (coarser segments) & $3.0-4.0$ & 1 reaction & 1.16 \\
\hline
\end{tabular}


Figure $14 \mathrm{~b}$ shows pressure curves in a perpendicular to the tank axis direction at $0.88 \mathrm{~ms}$ for five simulations. Two simulations are carried out with fully opened tank walls: without combustion (curve 1) and with combustion (37 reactions chemical mechanism, curve 2). The combustion increases the pressure throughout the distance (thus the impulse) with only a small increase of the blast wave maximum pressure. The pressure behind the blast wave drops to deep vacuum due to gas inertia for fully open tank walls. This is different for the segmented tank (curves 3 to 5), when there is still pressure above $200 \mathrm{kPa}$ kept inside the tank and a smaller vacuum (static pressure) is observed in the hydrogen "jetting" area close to the tank surface. There is a little difference between the finer and the coarser grid simulations. The tank segmentation increases the blast wave pressure and impulse in the near-field due to more intensive combustion by about twice.

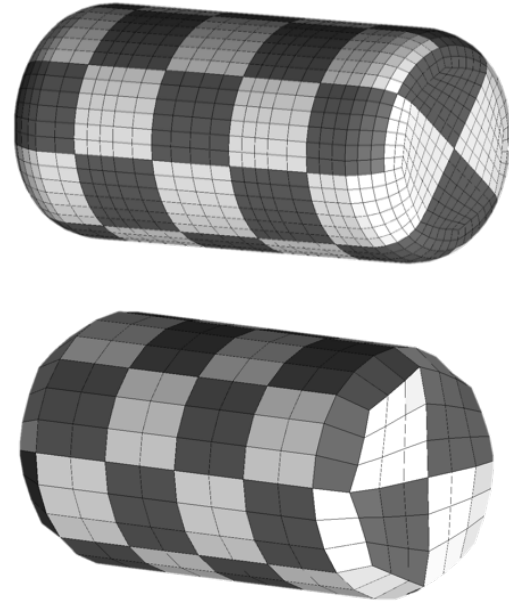

(a)

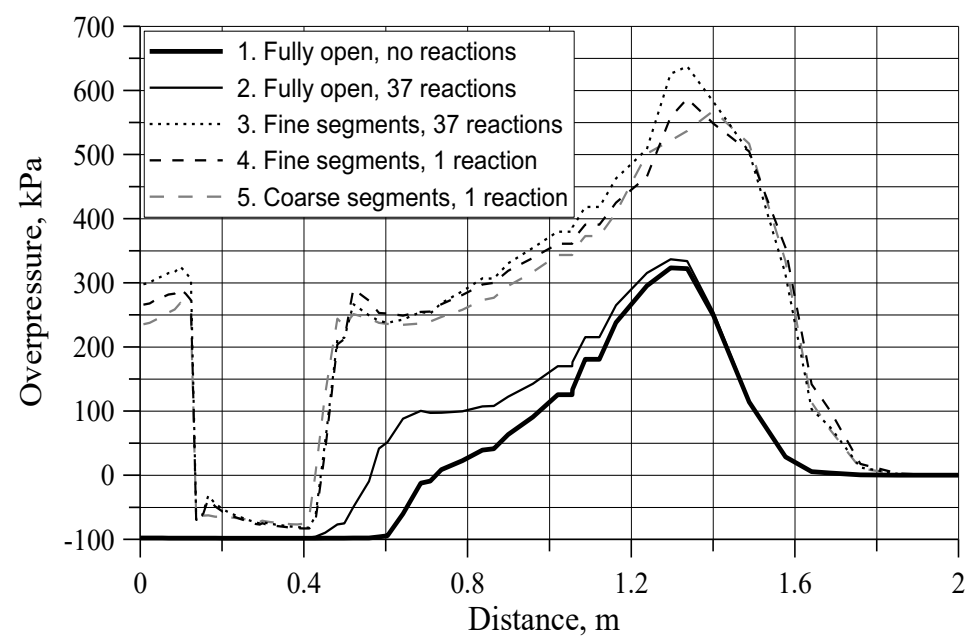

(b)

Figure 14. (a) - segmented tank with finer mesh (top) and coarser mesh (bottom). (b) - pressure distribution with distance perpendicular to the tank axis in the horizontal direction at time $0.88 \mathrm{~ms}$ for instantaneous full opening of the tank walls (solid lines) and only segments opening (dashed lines).

Thus, the presence of wall fragments (segmented tank simulations) during tank rupture could facilitate the generation of higher pressure and impulse in the blast wave, at least in the near field. However, the segmented tank with fixed closed areas changes the problem to hydrogen "jetting" through open segments rather than symmetrical high-pressure zone decay in conditions of moving fragments. This limits the conclusion to rather academic interest. Further effects of fragments, including hazards, are out of the scope of this study.

\subsubsection{Delayed opening of half tank wall}

To understand the difference between experimental and simulated peak overpressure at $5 \mathrm{~m}$ in Test 1 , simulations are performed for a scenario of the tank rupture into two halves (cut perpendicularly to the tank axis). This scenario is supported by experimental observations [8],[21]. The tank half in the sensor's direction is removed instantaneously, while the second half is removed instantaneously after $0.7 \mathrm{~ms}$. The second half opening delay time is calculated using the second Newton's Law, $F=m \cdot a$. The propulsion force is the product of burst pressure and cross-section area of the tank perpendicular to the tank axis $\left(0.053 \mathrm{~m}^{2}\right.$ for the tank diameter $\left.0.26 \mathrm{~m}\right)$. Assuming the tank mass is $37 \mathrm{~kg}$, the time required for the tank half to travel a distance when the lateral "open" area between two halves is equal to the tank cross-section area is $0.7 \mathrm{~ms}$.

Figure 13a above shows the effect of the tank wall opening it two steps on the pressure dynamics. The higher experimental pressure in Test 1 at $5 \mathrm{~m}$ (compared to experimental pressure in Test 2) is reproduced in this numerical experiment. The pressure peak at $5 \mathrm{~m}$ appears earlier compared to the instantaneous opening of the entire tank. The blast wave pressure is somewhat overpredicted at $10 \mathrm{~m}$, and the negative phase amplitude at $5 \mathrm{~m}$ is overestimated by 3 times. 
The comparison of hydrogen burned mass for the instantaneous opening of the entire tank wall and the two-stage opening (Test 1) allows concluding that the tank opening technique does not affect the hydrogen combustion rate (while strongly affects the pressure dynamics at $5 \mathrm{~m}$ ).

Figure 15 compares temperature profiles (cross-section perpendicular to the tank axis) at $40 \mathrm{~ms}$ for two scenarios of the tank wall opening and the ambient temperature in the experiment of $282 \mathrm{~K}$ (the minimum calculated temperature of expanded hydrogen at this time is $82 \mathrm{~K}$, i.e. in the first colour range in the figure). Apparently, the lower temperature of expanded hydrogen is observed for the case of instantaneous opening of the entire tank wall (Fig. 15a). The opening technique strongly affects the fireball shape. The fireball size enlarges horizontally for two-stage opening (Fig. 15b). Thus, we could assume that the problem formulation details could have a stronger effect of simulation results than the choice of sub-models of turbulence and combustion.

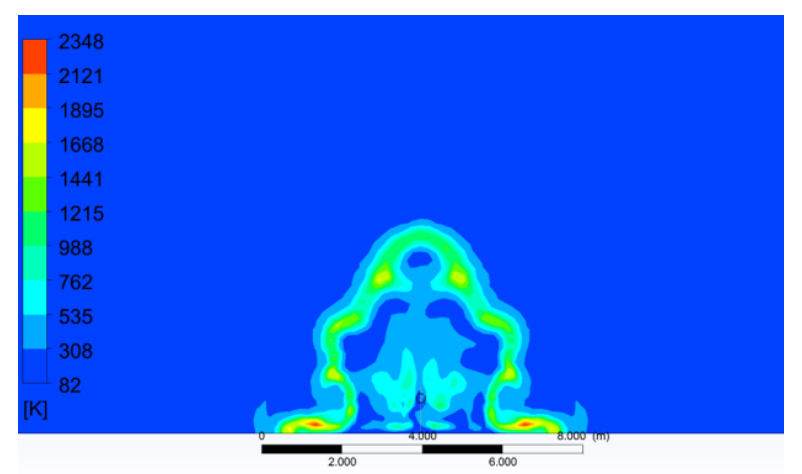

(a)

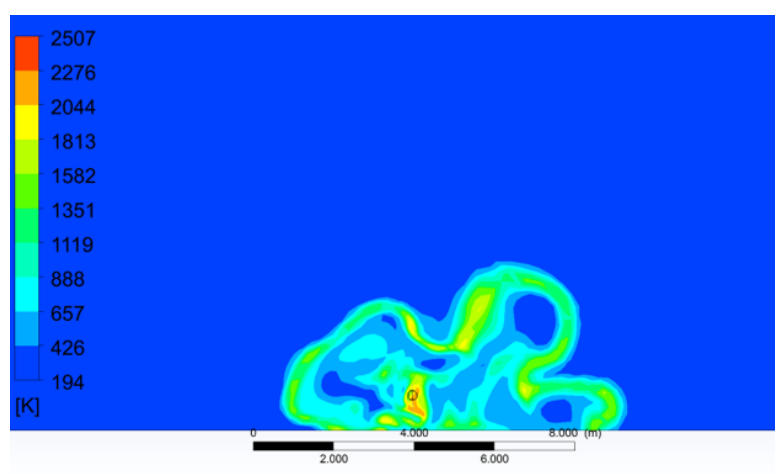

(b)

Figure 15. Temperature distribution in cross-section plane at $40 \mathrm{~ms}$ (Test 1). (a) - the instantaneous opening of the entire tank wall, (b) - delayed by 0.7 ms opening of half of the tank. The FRC and RNG sub-models.

Another case without removal of the second half of the tank at all is simulated. No difference in pressure dynamics at sensors and in a quantity of burnt hydrogen was observed.

\subsubsection{Hydrogen combustion and blast wave strength}

To quantify the contribution of hydrogen combustion to blast wave strength, a case with the release of only mechanical energy is simulated (combustion is deactivated). Figure $13 \mathrm{~b}$ shows the pressure transients at two sensors location (Test 2). The simulated without combustion pressure peaks at $5 \mathrm{~m}$ and $10 \mathrm{~m}$, i.e. 47 and $17 \mathrm{kPa}$ respectively, are below the experimental values. These values agree well with the overpressures calculated using Baker's methodology for high-pressure tank rupture that does not account for the contribution of combustion [22], i.e. 45.6 and $15.2 \mathrm{kPa}$ respectively. Thus, the methodology [22] of the blast wave pressure decay cannot be recommended for hydrogen safety engineering.

Figure $13 \mathrm{~b}$ demonstrates that hydrogen combustion contributes significantly to the blast wave strength. The release of chemical energy, while the contact surface is in the area of high pressure, increases the pressure peak by $37 \%$ at $5 \mathrm{~m}$, which is in line with the $30 \%$ increase of the maximum blast wave overpressure due to hydrogen combustion at distance $6.5 \mathrm{~m}$ in the USA test [5]. The blast arrival time is affected by combustion too. Due to lower shock pressure in the absence of combustion and thus lower shock propagation velocity, the simulated blast wave arrival is delayed by $1 \mathrm{~ms}$ for $5 \mathrm{~m}$ sensor and 2 $\mathrm{ms}$ for $10 \mathrm{~m}$ sensor. Therefore, the conclusion of theoretical study [5] is confirmed in this numerical study: the contribution of hydrogen combustion into the blast wave strength cannot be neglected for a proper assessment of hazard and associated risk from the blast.

\subsubsection{SGS turbulence sub-model effect}

LES simulations are performed with two SGS turbulence sub-models, i.e. RNG and Smagorinsky-Lilly sub-models. The change of an SGS turbulence model has an insignificant effect on the pressure transients. This is confirmed by the same burning rate of hydrogen during the fast-burning stage after 
tank rupture. The SGS turbulence model influences somewhat combustion at later stages, with Smagorinsky-Lilly model resulting in a higher amount of burnt hydrogen. This is though due to the more corrugated contact surface and a larger fireball size for this model.

\subsubsection{Radiation modelling effect}

The Discrete Ordinates (DO) model is employed, and the Radiative Transfer Equation is discretised using $5 \times 5$ angular divisions and $3 \times 3$ pixels, as suggested in [23] for problems involving large gradients of temperature. Water vapour is considered as a grey gas with a mean Planck absorption coefficient defined as a function of the CV temperature and water vapour partial pressure, using data in [24]. Results show that neither the pressure dynamics nor the amount of burnt hydrogen are affected by the inclusion of radiative heat transfer into simulations.

\subsubsection{Combustion sub-model effect}

The reaction rate of non-premixed turbulent combustion is controlled by turbulent mixing. The EDC sub-model of combustion performance is compared against the FRC sub-model for the case with a patch with a temperature equal to $900 \mathrm{~K}$ and water vapour mass fraction 0.01 imposed in the region $L \times W \times H=1.5 \times 0.9 \times 0.7 \mathrm{~m}$ surrounding the tank. The patch is implemented for all following simulations with the EDC model. The coarse grid with $147 \mathrm{k}$ CVs is employed. The one-step global chemical reaction is applied. Simulations are performed with $\mathrm{CFL}=0.1$. Figure 16 compares the simulation results for the two combustion sub-models. Pressure transients are practically not affected, whereas a slight effect on burnt hydrogen is observed. The conclusion can be drawn that both the EDC or the FRC submodels can be successfully used for simulation of blast wave dynamics.

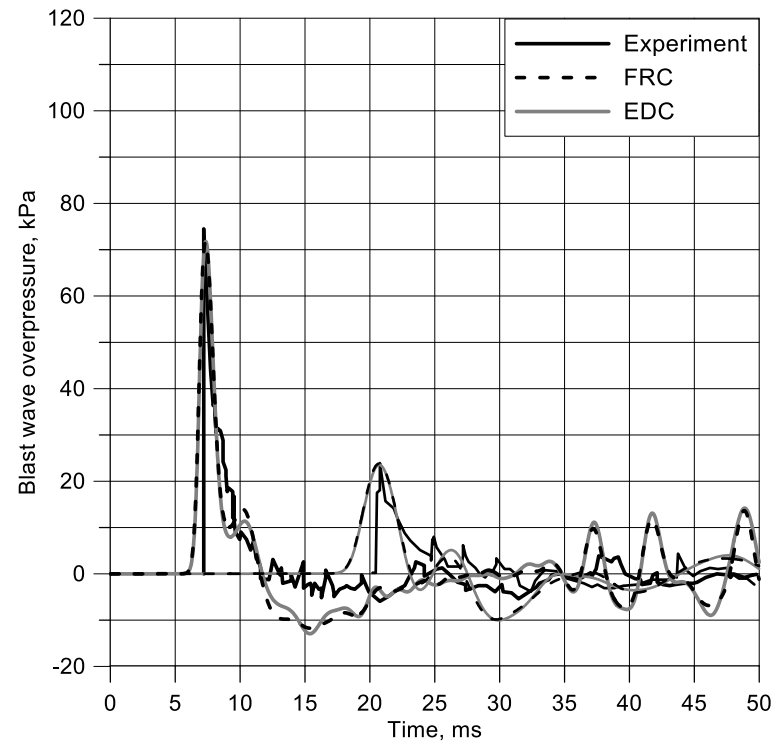

(a)

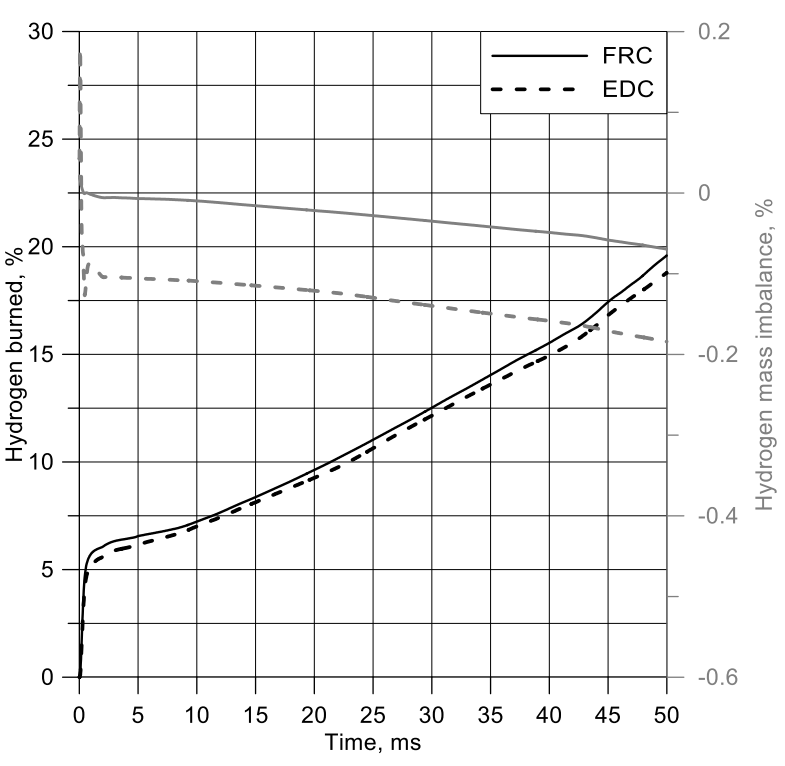

(b)

Figure 16. Simulations sensitivity to combustion sub-model (Test 2). (a) - pressure dynamics at $5 \mathrm{~m}$ and $10 \mathrm{~m}$; (b) - burned hydrogen and hydrogen mass balance. The Smagorinsky-Lilly sub-model of SGS turbulence.

\subsubsection{Fireball dynamics}

Simulations of the fireball with $\mathrm{CFL}=0.1$ until the complete hydrogen combustion are impractical. To avoid numerical instabilities, at $80 \mathrm{~ms}$ the imposed CFL was gradually increased by 10 times in $10 \mathrm{~ms}$ (total simulation time is 17 days on a 64 processors workstation). The increase of CFL didn't cause any variation to hydrogen mass balance change trend (Fig. 17a). Hydrogen mass imbalance is within $-0.8 \%$ until the simulations are complete at $2 \mathrm{~s}$ of real-time. Hydrogen combustion rate is highest at the beginning. Beyond $50 \mathrm{~ms}$ it decreases progressively until hydrogen is entirely burned. 


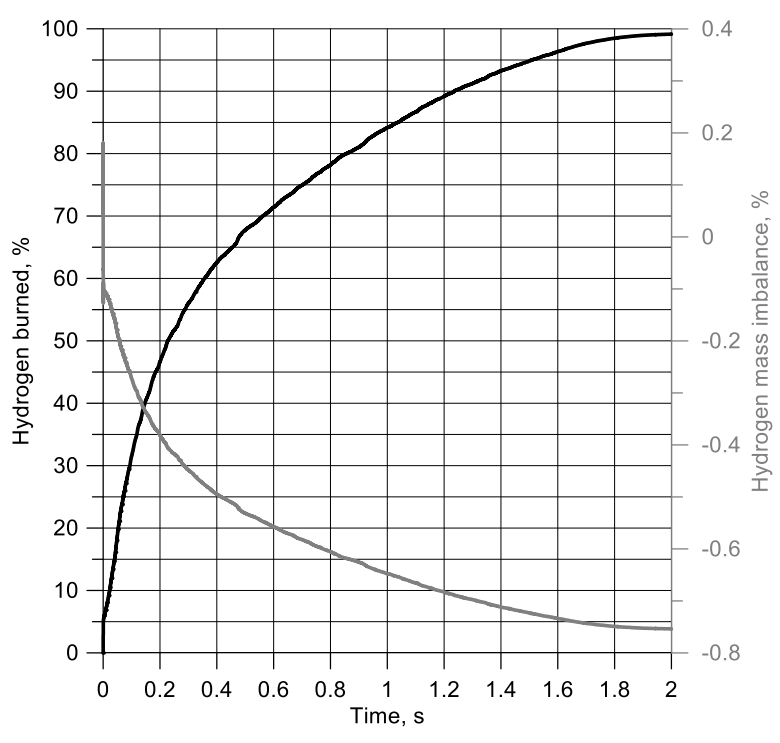

(a)

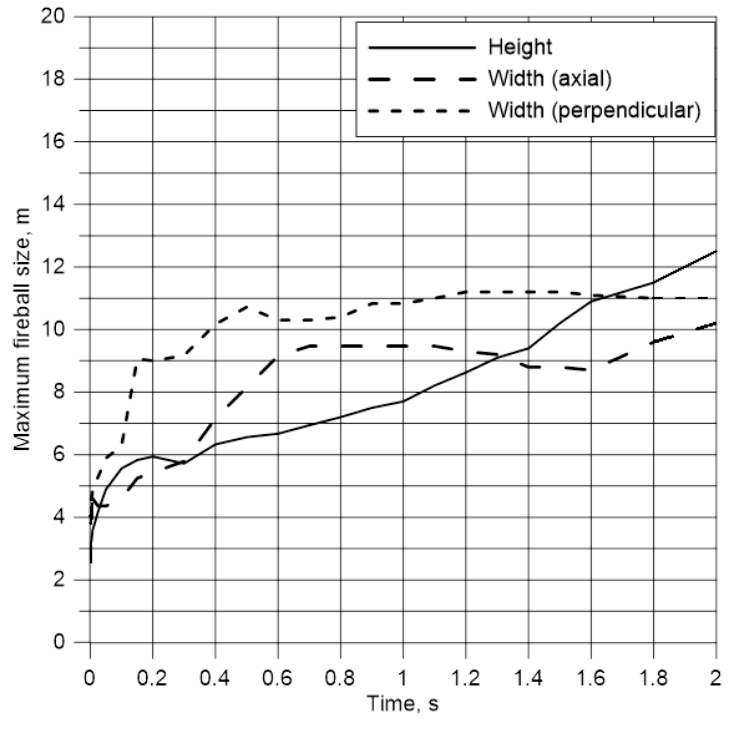

(b)

Figure 17. (a) - burned hydrogen (black curve, left Y-axis) and hydrogen mass imbalance (grey curve, right $\mathrm{Y}$-axis) until the end of hydrogen combustion in the fireball. (b) - maximum fireball size in two horizontal directions (dashed lines) and fireball height (solid line). Test 2. The Smagorinsky-Lilly and EDC sub-models.

Figure $17 \mathrm{~b}$ shows the fireball size dynamics during $2 \mathrm{~s}$. The fireball reaches a maximum horizontal size of $11 \mathrm{~m}$ at $500 \mathrm{~ms}$ in the direction perpendicular to the tank axis. Afterwards, the maximum horizontal size remains approximately constant throughout the combustion duration (see also snapshots in Fig. 19). After $800 \mathrm{~ms}$, buoyancy dominates fireball dynamics and leads to its lift-off from the ground. The fireball height at $2 \mathrm{~s}$ is $12.5 \mathrm{~m}$. Fireball snapshot at " $2000 \mathrm{ms"} \mathrm{(Fig.} \mathrm{19)} \mathrm{is} \mathrm{scaled} \mathrm{down} \mathrm{by} 8 / 5$ times to show the rising combustion products. At this time fireball has completely detached from the ground and the maximum hydrogen concentration in the domain is below the LFL. Consequently, this is considered as the endpoint in simulations, given that there is no further hydrogen available to burn (even if a small amount of hydrogen is still in the domain).

Figure 18 shows the dynamics of pressure, temperature, hydrogen and water vapour mole fractions from $0 \mathrm{~ms}$ to $8 \mathrm{~ms}$, when the blast wave reaches the second sensor (Test 2). Legend limits for pressure and temperature are different at snapshots $0 \mathrm{~ms}$ and $0.5 \mathrm{~ms}$ due to the larger variation in the parameter's range. The figure is zoomed in by more than 5 times for snapshot $0 \mathrm{~ms}$ to better show the initial conditions in the domain, the hydrogen tank and the patch surrounding the tank. The starting shock compresses air causing temperature increase to $2500 \mathrm{~K}$ (hydrogen temperature decreases significantly due to expansion down to established limit $30 \mathrm{~K}$ to prevent unphysical solutions due to not simulated phenomena like condensation, etc). The temperature rises $3200 \mathrm{~K}$ when the shock wave reflects from the ground at $0.5 \mathrm{~ms}$. The reflected blast moves faster compared to the primary blast due to the higher temperature of combustion products it propagates through (snapshot $2 \mathrm{~ms}$ ). The reflected blast catches up with the primary wave propagating through the air and they combine in a singular front at approximately $5 \mathrm{~ms}$. Snapshots of pressure and hydrogen demonstrate the detachment between the blast wave and the contact surface.

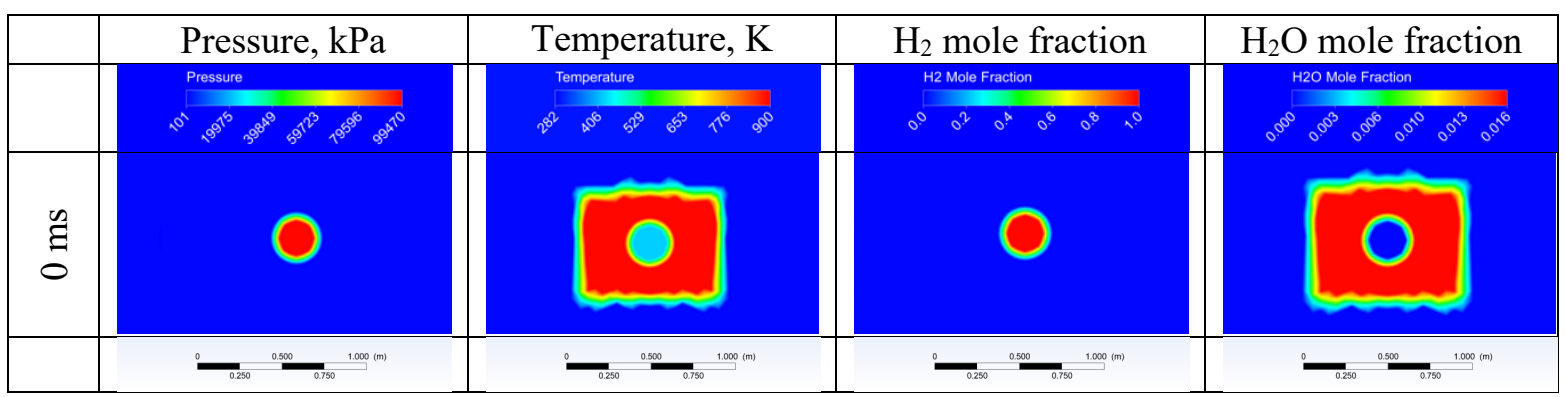




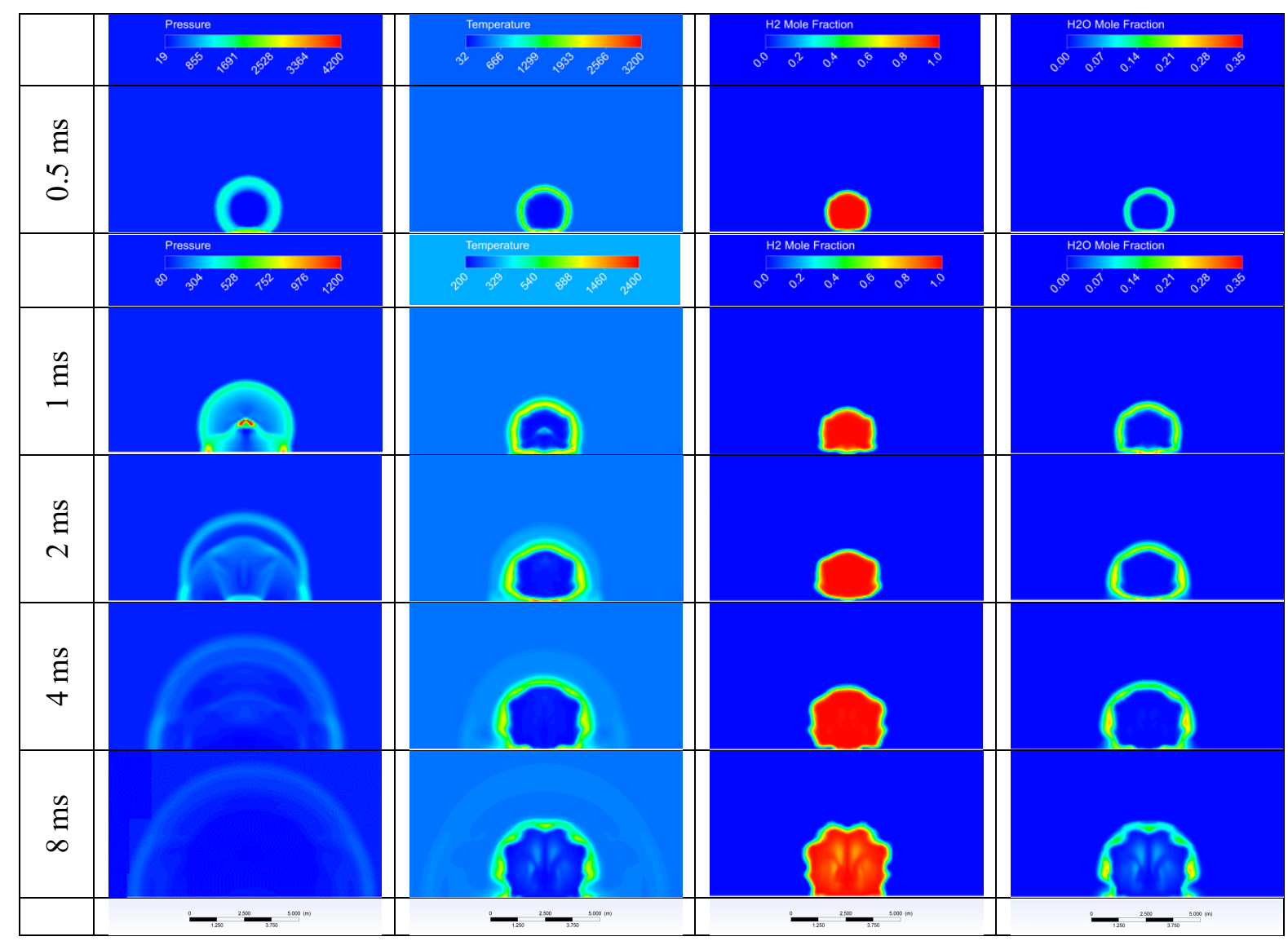

Figure 18. Dynamics of pressure, temperature, the mass fraction of hydrogen and water vapour at time $0-8 \mathrm{~ms}$ for Test 2 . The plane perpendicular to the tank axis. The Smagorinsky-Lilly and EDC submodels $(\mathrm{CFL}=0.1)$.

Figure 18 illustrates that the instabilities deform the contact surface and thus increase the combustion area. The deformation can be caused by Rayleigh-Taylor instability when contact surface between gases accelerates in the direction from lighter to the heavier gas. At the initial stage, the combustion manifests mainly at the near-spherical contact surface where the cooled by expansion hydrogen reacts with heated by the shock compression oxygen of the air. Then, the instabilities develop at the contact surface, e.g. snapshot $8 \mathrm{~ms}$.

Figure 19 shows that at later stages $(25-2000 \mathrm{~ms})$ different scales of flow instabilities and non-premixed turbulent combustion strongly deform the contact surface further.

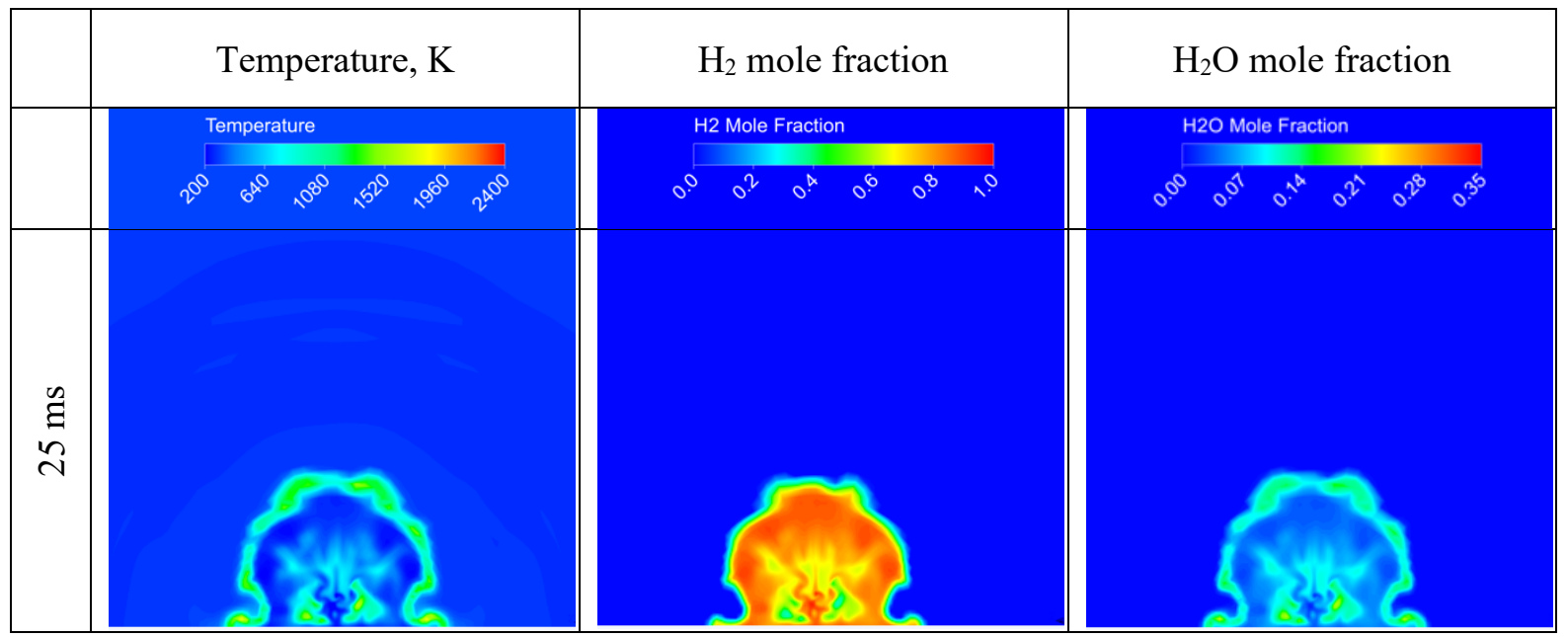




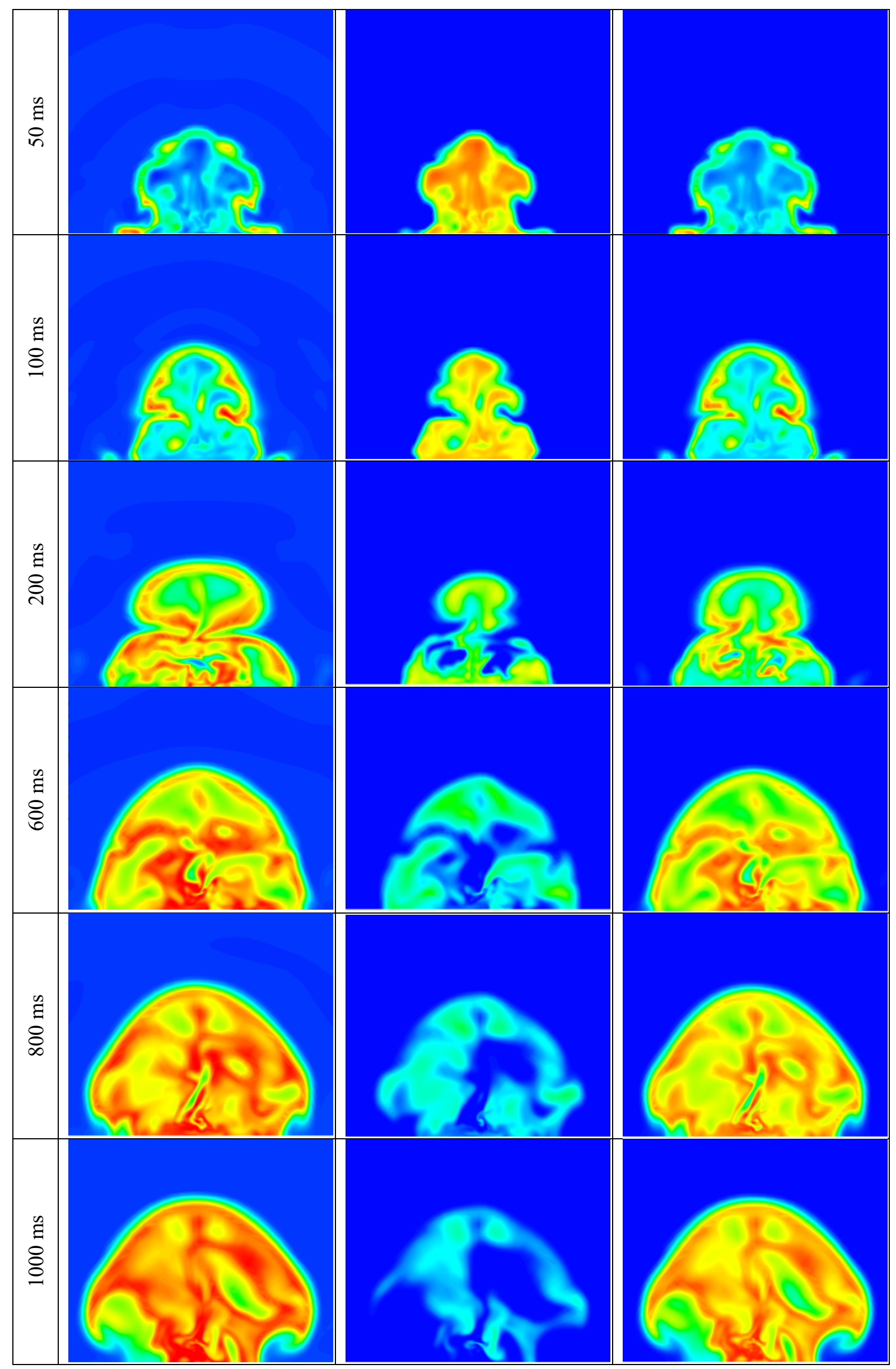




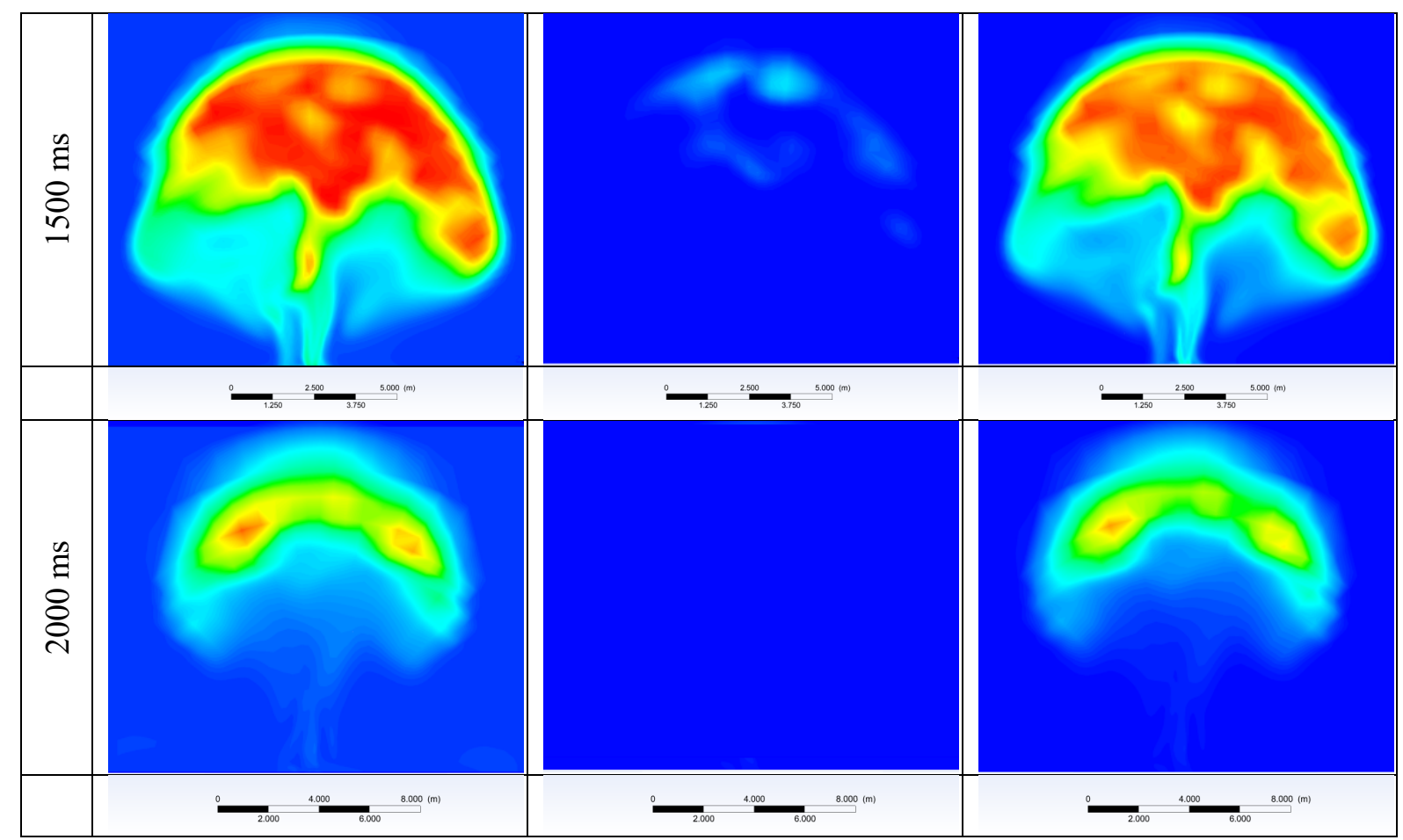

Figure 19. Dynamics of temperature, the mole fraction of hydrogen and water vapour at 25-2000 ms on perpendicular to the tank axis plane for Test 2. The Smagorinsky-Lilly and EDC sub-models. Note: snapshot "2000 ms" is scaled down by $8 / 5$ times.

The simulated fireball is hemispherical with a maximum diameter of about $11 \mathrm{~m}$. This is equal to the diameter of the hemisphere that can be calculated by the existing correlations based on the fuel mass and the assumption of complete combustion. The difference with the maximum fireball size of $18 \mathrm{~m}$ reported in the experimental paper [9] can be explained by the fact that the experimental shape of the fireball is not hemispherical and is rather flattened. The experimental fireball develops mainly horizontally while expansion upwards is limited. This is believed due to the inertial opening of the tank as per simulations above for the two-stage tank opening and presence of the burner. The simulations show almost hemispherical fireball with a height similar to the horizontal size. The authors of the experiment [9] stated that turbulence in the vicinity of the tank surface is particularly enhanced because of its fragmentation. This, along with the rupture into large fragments [8], [21], can severely affect the fireball shape and thus maximum size, e.g. due to non-symmetrical (elongated) shape and possible engulfment of air pockets between multiple "jets" of hydrogen and combustion products. The effect of this air engulfment into the fireball on its shape and size is noticed to some extent in the simulations when considering the two-stage opening of the tank. Furthermore, simulations do not consider the entrainment of dust and sand/soil into the fireball during ground cratering. In reality, flying particulates heated by high temperature combustion products can affect the fireball dimensions recorded by cameras.

\subsubsection{Effect of discretisation scheme for convective terms}

In simulations discussed above with the EDC sub-model, a second-order upwind scheme is applied for the spatial discretisation of convective terms in the governing equations, as a high Peclet number $(\mathrm{Pe})$ is expected. The simulations confirmed that local $P e$ is larger than 2 in almost all zones of interest at early combustion stage up to $60 \mathrm{~ms}$. However, central differencing (CD) based schemes are generally recommended for all equations when using LES [23]. If a convective flux starts to dominate a diffusive flux, i.e. for local $P e>1$, the CD scheme can produce non-physical oscillations and unbounded solutions, leading to stability problems. A bounded central differencing (BCD) scheme should be used instead to tackle those oscillations by bounding the solution. 
The effect of a discretisation scheme is analysed by implementing the BCD scheme for all convective terms. The use of BCD scheme causes an increase of the burned hydrogen mass, up to an additional $6 \%$ at $50 \mathrm{~ms}$. BCD scheme in Fluent is realised as a composite of CD scheme, blend of CD and $2^{\text {nd }}$ order upwind schemes, and $1^{\text {st }}$ order upwind scheme [23]. The BCD scheme introduces limits on the values of variables to suppress extraneous overshoots or nonmonotonic oscillations, and it may reduce to $1^{\text {st }}$ order upwind for increasingly large $P e$ number [25]. This is consistent with the observed larger combustion rate, given that the $1^{\text {st }}$ order upwind scheme is more diffusive than $2^{\text {nd }}$ order, and it may provide a more intensive mixing partly due to numerical diffusion. A corresponding increase of overpressure is observed, up to $+35 \%$ for a $5 \mathrm{~m}$ sensor.

Following the considerations on the Peclet number and the conclusions drawn from the simulation results, the $2^{\text {nd }}$ order upwind scheme is confirmed to be a better choice for the discretisation to reproduce experimental pressure dynamics.

\subsubsection{Grid sensitivity study}

Table 2 presents the parameters of the four grids investigated. The minimum CV size is calculated approximating the cell as a cube. By the time $2.4 \mathrm{~ms}$ after tank rupture simulations on Grid 4 were stopped due to unacceptably long CPU time of 26 days (the blast wave did not arrive at $5 \mathrm{~m}$ yet, preventing comparison of results for Grid 4 with experimental pressure transient). All simulations are performed with $\mathrm{CFL}=0.1$ (up to $80 \mathrm{~ms}$ for Grid 1, increased timestep afterwards).

Table 2. Parameters of four numerical grids and simulation performance.

\begin{tabular}{|c|c|c|c|c|c|c|}
\hline $\begin{array}{c}\text { Grid } \\
\text { identifier }\end{array}$ & $\begin{array}{c}\text { Total CVs } \\
\text { number }\end{array}$ & $\begin{array}{c}\text { Minimum } \\
\mathrm{CV} \text { volume, } \\
\mathrm{m}^{3}\end{array}$ & $\begin{array}{c}\text { Minimum } \\
\mathrm{CV} \text { size, } \\
\mathrm{m}\end{array}$ & $\begin{array}{c}\text { Total } \\
\text { simulated } \\
\text { time, } \mathrm{ms}\end{array}$ & $\begin{array}{c}\text { Total } \\
\text { simulation } \\
\text { time, days }\end{array}$ & $\begin{array}{c}\text { CPU time to } \\
\text { simulate } 2.4 \\
\mathrm{~ms}, \text { days }\end{array}$ \\
\hline Grid 1 & 147,104 & $8.12 \cdot 10^{-6}$ & $2.0 \cdot 10^{-2}$ & 2,000 & 17 & $0.2(4.5 \mathrm{~h})$ \\
\hline Grid 2 & 723,044 & $7.73 \cdot 10^{-7}$ & $9.2 \cdot 10^{-3}$ & 52 & 22 & 1.5 \\
\hline Grid 3 & $2,401,128$ & $1.71 \cdot 10^{-7}$ & $5.6 \cdot 10^{-3}$ & 16 & 34 & 7.5 \\
\hline Grid 4 & $8,980,412$ & $4.25 \cdot 10^{-8}$ & $3.5 \cdot 10^{-3}$ & 2.4 & 26 & 26 \\
\hline
\end{tabular}

Figure 20a compares the experimental pressure dynamics for Test 2 and pressure transients simulated on Grids $1-3$ at $5 \mathrm{~m}$ and $10 \mathrm{~m}$. The pressure peak at $5 \mathrm{~m}$ insignificantly increases from $71.8 \mathrm{kPa}$ (Grid 1) to $73.5 \mathrm{kPa}$ (Grid 2). Pressure peak on Grid 3 is $69.4 \mathrm{kPa}$, i.e. $6 \%$ less compared to Grid 2. The experimental pressure peak is $74.4 \mathrm{kPa}$ and reproduced closely in simulations on all grids (Grids 1-3). Experimental pressure dynamics at $10 \mathrm{~m}$ (thin solid lines) is compared with simulations only for Grids 1-2 (simulated time for Grid 3 of $16 \mathrm{~ms}$ during 34 days is insufficient). Simulations on Grids 1-2 resulted in pressure peaks of $23.5 \mathrm{kPa}$ and $22.3 \mathrm{kPa}$ respectively, thus closely reproducing experimental overpressure of $23.9 \mathrm{kPa}$. Arrival time of the blast wave is practically not affected by the grid refinement, despite the lower amount of burned hydrogen (Fig. 20b) for the finer meshes (Grids 2-3). Pressure oscillations with an amplitude of approximately $10 \mathrm{kPa}$ are observed at $5 \mathrm{~m}$ for Grid 1 beyond $35 \mathrm{~ms}$. These oscillations originate from the combustion zone and are sensed at $5 \mathrm{~m}$, whereas they dissipate at $10 \mathrm{~m}$. The pressure oscillations are reduced for Grid 2 to comparable with the experimental amplitude.

Figure 20b shows the hydrogen burned mass dynamics for Grids 1-4. The grid refinement leads to a notable decrease of the burned hydrogen at the start of the process. The difference decreases with time. The mass imbalance improves with the refinement level as expected. The decrease of CV size leads to a reduction of the contact surface "volume", which occupies 3-5 CVs thus leading, expectedly, to a smaller quantity of burnt hydrogen. 


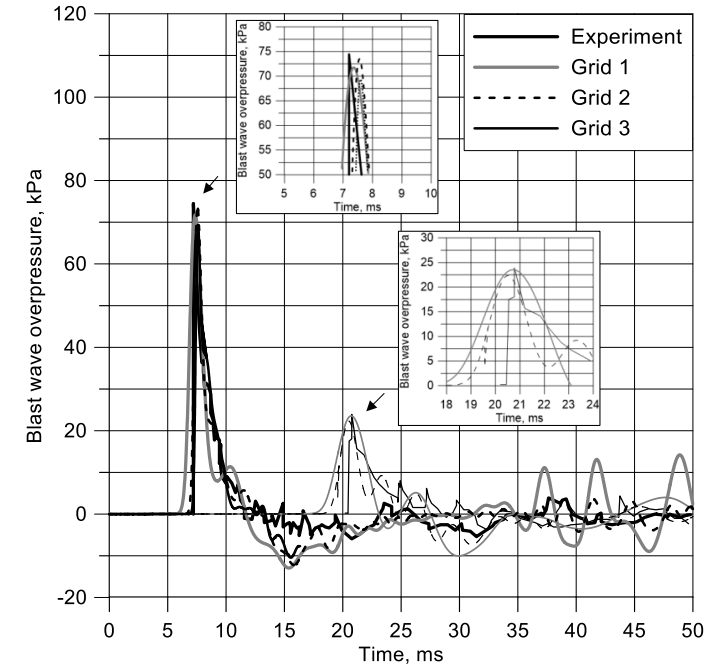

(a)

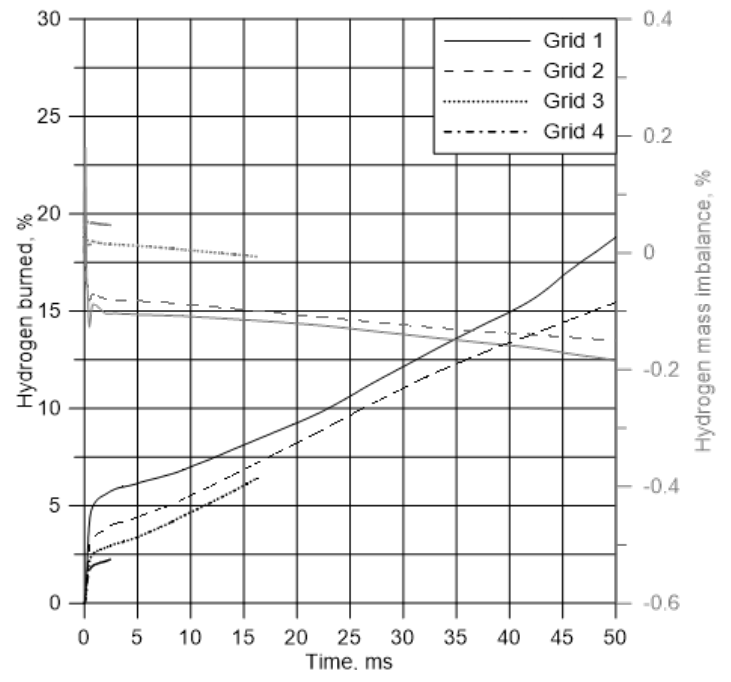

(b)

Figure 20. Grid sensitivity for Test 2. (a) - pressure dynamics at $5 \mathrm{~m}$ (thick lines) and $10 \mathrm{~m}$ (thin lines); (b) - burned hydrogen (black lines, left Y-axis) and hydrogen mass imbalance (grey lines, right Y-axis). The Smagorinsky-Lilly and EDC sub-models.

The conclusion from the analysis of the pressure and burned hydrogen mass transients in Fig. 20 is that the maximum blast wave pressure is preserved on different grids although released during combustion chemical energy decreases with mesh size. The question is where the larger released on the coarser grid chemical energy is deposited if the maximum blast wave pressure does not change?

Figure 21 shows pressure (black lines) and impulse (grey lines) dynamics for Grids 1-4. Simulations demonstrate that the coarser is the grid the larger is the blast wave impulse, i.e. the integral of blast wave pressure in time. Thus, there is no "loss" of "increased" chemical energy but its growth for coarser grids is associated with the blast wave impulse increase while maximum pressure is practically not affected. The grid sensitivity analysis allows concluding that while Grid 1 is indeed quite coarse and "generates" $20 \%$ higher impulse, the practical convergence is observed for Grids 2 and 3 already at 5 $\mathrm{m}$ with negligible difference in maximum pressure and an acceptable difference in the positive impulse.

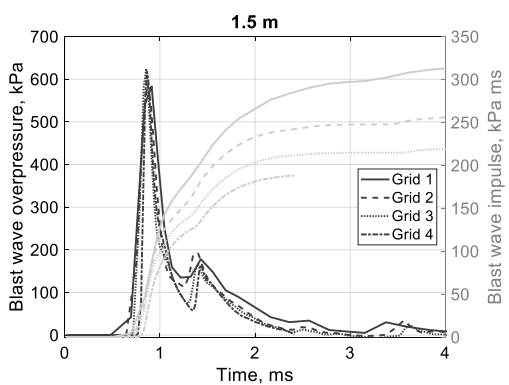

(a)

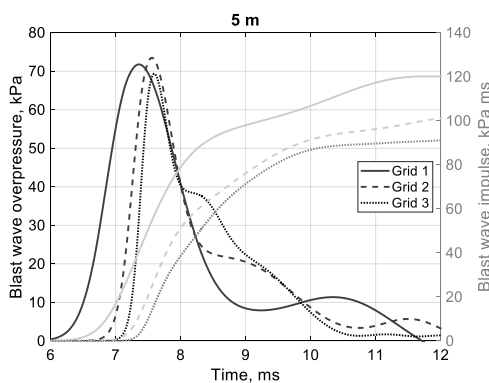

(b)

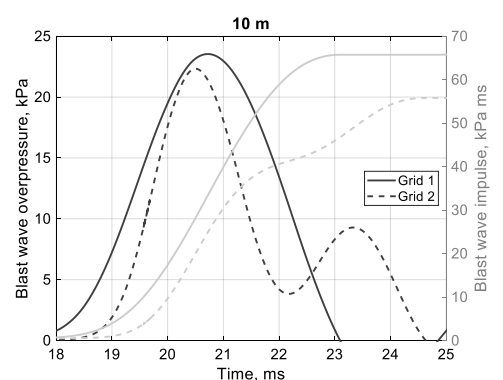

(c)

Figure 21. Pressure (black, left $\mathrm{Y}$-axis)) and impulse (grey, right $\mathrm{Y}$-axis) dynamics for Test 2 at different distances from the tank: (a) - $1.5 \mathrm{~m}$ for Grids 1-4; (b) - $5 \mathrm{~m}$ for Grids 1-3; (c) - $10 \mathrm{~m}$ for Grids 1-2. The Smagorinsky-Lilly and EDC sub-models.

\section{CONCLUSIONS}

The significance of this work is in the development and validation of the CFD model to simulate blast wave and fireball dynamics after stand-alone high-pressure hydrogen tank rupture in a fire in the open atmosphere. The complementarities and synergy of experimental data and numerical analysis allowed 
to get insights into blast wave and fireball dynamics, and thus close knowledge gaps in understanding of underlying physical phenomena.

The release of chemical energy during combustion at the contact surface contributes to the maximum blast wave pressure compared to tank rupture without combustion. Combustion contributes also to the pressure profile and thus the impulse. The grid refinement (decrease of mesh size) practically does not affect the maximum pressure in the blast wave but reduces its impulse until the convergence is achieved.

The validated CFD model can be used as a contemporary predictive tool for assessment of consequences in case of tank rupture in a fire. The model is an essential contribution to hydrogen safety engineering to define hazard distances for scenarios of hydrogen storage rupture in a fire in complex geometries, develop novel mitigation strategies and engineering solutions for hydrogen systems and infrastructure, etc.

Parametric studies are carried out to understand the effect of different physical sub-models, numerical methods and other model parameters on the predictive capability of the CFD model. The convergence of the solution is found at $\mathrm{CFL}=0.1-0.2$ which are below values $\mathrm{CFL}=0.7-0.9$ applied in simulations of deflagrations. The CFD model is flexible to the use of alternative sub-models of sub-grid scale turbulence (Smagorinsly-Lilly, RNG) and combustion (EDC, FRC). It is demonstrated that for closer reproduction of experimental data it is more important to properly formulate the problem and account for details, e.g. the presence of burner pan and non-instantaneous opening of the tank walls, etc.

The originality of this study is in bringing together physical and numerical models to simulate complex phenomena following a tank rupture in a fire. This is the first study explaining the mechanism of hydrogen combustion contribution to the blast wave strength. The mechanism is not only understood yet quantitatively assessed. For example, hydrogen combustion after 36 litres $70 \mathrm{MPa}$ tank rupture in a fire increases the maximum blast wave overpressure at $5 \mathrm{~m}$ by $37 \%$.

The originality of the research includes the investigation of the effect of the tank rupture modality. It is demonstrated that the inertial tank wall opening can strongly affect the blast wave overpressure in the near field and the fireball shape.

The use of ideal gas chemistry instead of a real gas is verified by the fact that pressure of the starting shock and thus at the contact surface between hydrogen and air falls below the non-ideal gas behaviour threshold of $10 \mathrm{MPa}$. The CFD model conserves the mechanical energy of real gas by re-scaling of tank volume with ideal gas used in simulations.

The use of an original adaptive time step by implementing a super-imposed CFL $\leq 0.1-0.2$ is seen to significantly reduce the computational costs while ensuring a hydrogen mass imbalance (as a parameter controlling simulations quality) below $0.5 \%$. Further efforts to decrease computational costs include the use of a global one-step reaction scheme instead of 37 reaction mechanism to reduce the calculation time by a factor of four without losing the accuracy of the blast wave and fireball dynamics simulations.

The rigour of this research is in the validation of the CFD model against all experimental data available to the authors from the literature. The validation domain includes destructive fire tests with tank carried out in the USA (NWP=35 MPa tank) and Japan (NWP=70 MPa tanks) at burst pressure up to $99.5 \mathrm{MPa}$. The simulations successfully reproduced experimental pressure transients at different distances from a tank as well as fireball size and shape where applicable.

Recreation of initial condition before tank rupture and inclusion of burner pan geometry aid in an overall better reproduced near-field blast wave overpressure as seen in the experiments, e.g. the sub-peak on the descending pressure part of the blast wave.

The higher experimentally observed pressures in the direction perpendicular to a tank axis compared to the direction along the tank in the near field are well reproduced in the simulations.

The simulated fireball is seen to display typical development during a growth stage before rising with buoyancy effects. Ultimately, it is seen to accurately reproduce the fireball size and shape in the USA experiment ( $7.7 \mathrm{~m}$ after $45 \mathrm{~ms})$. 


\section{ACKNOWLEDGEMENTS}

The authors are grateful to Engineering and Physical Sciences Research Council (EPSRC) of the UK for funding this work through SUPERGEN Hydrogen and Fuel Cell Hub project (EP/P024807/1), and to Fuel Cells and Hydrogen 2 Joint Undertaking (FCH2 JU) for funding this research through the HyTunnel-CS project "Pre-normative research for safety of hydrogen driven vehicles and transport through tunnels and similar confined spaces". The HyTunnel-CS project has received funding from the FCH2 JU under grant agreement No.826193. This Joint Undertaking receives support from the European Union's Horizon 2020 research and innovation programme, Hydrogen Europe and Hydrogen Europe Research.

\section{REFERENCES}

[1] Hwang HT, Varma A. Hydrogen storage for fuel cell vehicles. Curr Opin Chem Eng 2014;5:4248. https://doi.org/10.1016/j.coche.2014.04.004.

[2] Gambone L, Wong J. Fire protection strategy for compressed hydrogen-powered vehicles. In: 2nd International Conference on Hydrogen Safety, San Sebastian, Spain, 2007.

[3] Wong J. CNG \& hydrogen tank safety, R\&D, and testing. In: CNG and Hydrogen Lessons Learned Workshop, Powertech Labs Inc., 12-Oct-2009.

[4] Dadashzadeh M, Kashkarov S, Makarov D, Molkov V. Risk assessment methodology for onboard hydrogen storage. Int J Hydrogen Energy 2018;43(12):6462-6475. https://doi.org/10.1016/j.ijhydene.2018.01.195.

[5] Molkov V, Kashkarov S. Blast wave from a high-pressure gas tank rupture in a fire: Stand-alone and under-vehicle hydrogen tanks. Int J Hydrogen Energy 2015;40(36):12581-12603. https://doi.org/10.1016/j.ijhydene.2015.07.001.

[6] Weyandt N. Analysis of Induced catastrophic failure of a 5000 psig type IV hydrogen cylinder. Southwest Research Institute Report for the Motor Vehicle Fire Research Institute; 2005. 01.06939.01.001.

[7] Zalosh R, Weyandt N. Hydrogen fuel tank fire exposure burst test. SAE Pap 2005;2005-01-1886.

[8] Zalosh R. Blast waves and fireballs generated by hydrogen fuel tank rupture during fire exposure. In: 5th International Seminar on Fire and Explosion Hazards, Edinburgh, UK; 2007.

[9] Tamura Y, Takahashi M, Maeda Y, Mitsuishi H, Suzuki J, Watanabe S. Fire exposure burst test of $70 \mathrm{MPa}$ automobile high-pressure hydrogen Cylinders. In Society of Automotive Engineers of Japan Annual Autumn Congress, Sapporo, 2006.

[10] Steiner H, Gretler W. The propagation of spherical and cylindrical shock waves in real gases. Phys. Fluids 1994;6(6):2154-2164. https://doi.org/10.1063/1.868218.

[11] Magnussen BF. The Eddy Dissipation Concept. A bridge between science and technology. 2005.

[12]Pope SB. Computationally efficient implementation of combustion chemistry using in situ adaptive tabulation. Combust Theory Model 1997;1:41-63.

[13] Bragin MV, Makarov DV, Molkov VV. Pressure limit of hydrogen spontaneous ignition in a Tshaped channel. Int J Hydrogen Energy 2013;38(19):8039-8052. https://doi.org/10.1016/j.ijhydene.2013.03.030.

[14]Yakhot V, Orszag SA. Renormalization group analysis of turbulence. J Sci Comput 1986;1(1):151.

[15] Smagorinsky J. General circulation experiments with the primitive equations. I. The basic experiment. Mon Weather Rev 1963;91:99-164.

[16] Murthy JY, Mathur SR. A finite volume method for radiative heat transfer using unstructured meshes. J Quant Spectrosc Radiat Transf 1998;12(12):313-321.

[17] High HG. Design of small vessel rupture containment systems. Hazards 1989; p.141.

[18]Baker WE, Cox PA, Westine PS, Kulesz JJ, Strehlow RA. Explosion hazards and evaluation. Elsevier Scientific Publishing Company; 1983.

[19] Varma AK, Chatwani AU, Bracco FV. Studies of premixed laminar hydrogen-air flames using elementary and global kinetics models. Combustion and Flame 1986;64(2):233-236.

[20] Geng J, Baker Q, Thomas K. Pressure vessel burst directional effects. In: ASME 2011 Pressure Vessels and Piping Conference: Volume 4, Baltimore, Maryland, USA, 2011, pp. 3-9, doi: 10.1115/PVP2011-57167. 
[21]Pittman JF. Blast and Fragments from Superpressure Vessel Rupture. Naval Surface Weapons Center, White Oak Laboratory, Silver Spring, Maryland, 1976.

[22] Baker WE, Kulesz JJ, Ricker RE, Bessey RL, Westine PS, Parr VB, et al. Workbook for predicting pressure wave and fragment effects of exploding propellant tanks and gas storage vessels. Technical Report NASA-CR-134906. 1975.

[23]“ANSYS FLUENT 12.0 User's Guide.” [Online]. Available: https://www.afs.enea.it/project/neptunius/docs/fluent/html/ug/main_pre.htm. [Accessed: 21-Jan2020].

[24]Yan L, Yue G, He B. Development of an absorption coefficient calculation method potential for combustion and gasification simulations. Int J Heat Mass Tran 2015;91:1069-77.

[25]Leonard BP. The ULTIMATE conservative difference scheme applied to unsteady onedimensional advection. Comput Methods Appl Mech Eng. 1991;88(1):17-74. https://doi.org/10.1016/0045-7825(91)90232-U.

[26] Weinman KA, van der Ven H, Mockett CR, Knopp TA, Kok JC, Perrin RTE, Thiele FH. A study of grid convergence issues for the simulation of the massively separated flow around a stalled airfoil using des and related methods. In: European Conference on Computational Fluid Dynamics, ECCOMAS CFD, TU Delft, The Netherlands, 2006. 